\title{
FORMACIÓN DEL PROFESORADO UNIVERSITARIO HACIA EL AÑO 2020: MODELOS EDUCATIVOS DE VANGUARDIA PARA LA DOCENCIA AGROPECUARIA DE ALTA COMPETENCIA EN EL ECUADOR
}

\author{
TRAINING OF UNIVERSITY TEACHERS TOWARDS 2020: STATE-OF-ART \\ EDUCATIONAL MODELS FOR HIGH-COMPETITIVE AGRICULTURAL TEACHING \\ IN ECUADOR
}

JOHN E. FRANCO RODRÍGUEZ1', LUIS ORTIZ JIMÉNEZ2 ${ }^{2}$ ZOILA M. PALACIOS RABASCO ${ }^{3}$

\footnotetext{
1 Universidad Católica de Santiago de Guayaquil.john.franco@cu.ucsg.edu.ec

2 Departamento de Didáctica Escolar, Universidad de Almería, España. lortizj@ual.es

3 Escuela Superior Politécnica del Litoral, ESPOL. zpalacio@espol.edu.ec
}

RESUMEN

Este artículo de reflexión teórica, ha sido diseñado en el marco de la investigación doctoral Necesidades de formación de un profesorado competente en las Carreras Agropecuarias de la Universidad Católica de Santiago de Guayaquil,Ecuador, con proyección al horizonte 2020, que se integra en el Programa de Doctorado en Educación de la Universidad de Almería, España. Se constituye en un medio de expresión del equipo investigador con relación a los modelos de formación universitaria que se manejan en América y Europa, y que sirven de antecedentes para el redireccionamiento de una propuesta educativa en la institución de acogida en el Ecuador. Se revisaron los principales modelos educativos que interactúan en el ámbito internacional en atención a su estructura por competencias generales y específicas que implica una tentativa para poder acreditar similitud, equiparación, homologación entre las tendencias internacionales. Es un documento que permite valorar las competencias requeridas para atender la formación de profesionales universitarios de excelencia en el mundo contemporáneo.

PALABRAS CLAVE: competencias, modelo educativo, educación virtual, proyecto tunning.
ABSTRACT

This article theoretical reflection, has been designed as part of the doctoral research called Training needs of competent teachers in agricultural courses at the Catholic University of Santiago de Guayaquil, Ecuador, with projection to 2020, which integrates the Ph. D. program in Education at the University of Almeria, Spain. It becomes a means of expression of the research team regarding models of university education that are used in America and Europe, and that somehow serve as background for forwarding an educational proposal in the host institution in Ecuador. The main educational models that interact in the international arena in view of their structure general and specific skills that involves an attempt to prove similarity, matching, approval among international trends are reviewed. It is a document which evaluates the skills required to meet the professional training of university excellence in the contemporary world.

KEYWORDS: competencies, educational model, virtual education, tunning project. 
La academia cumple hoy por hoy, varios roles primordiales, entre ellos, y en primera instancia el de educar, así como también, el de orientar la cultura organizacional de la sociedad (Fernández, 2009), por lo que es necesario que exista una bidireccionalidad en los ámbitos de trabajo en la misma. Ya es sabido que el desarrollo de los pueblos se dirige hacia dónde lo lleva la universidad.

A partir de la Declaración Universal de los Derechos Humanos por parte de la Organización de las Naciones Unidas (ONU), en su Art. 26, la educación superior debe ser concebida bajo preceptos universales: para todas las personas, sin distingo de clases sociales, orientación sexual, edades, culturas, razas, etnias y condición humana, religiones o filiaciones políticas; con posibilidades de ser gratuita, al menos a nivel fundamental, siendo la formación de nivel básico, obligatoria, haciéndose especial mención el acceso a los estudios superiores en condiciones de igualdad y atención a las capacidades y méritos que los individuos evidencien "méritos respectivos". La Organización de los Estados Iberoamericanos para la Educación, la Ciencia y la Cultura (OEI), en su libro Metas Educativas 2021, plantea que "la educación que queremos para la generación de los Bicentenarios, tiene establecidas las expectativas (metas)» (OEI, 2010, p.147), las cuales se muestran en la Tabla 1.

\section{TABLA 1. METAS 2021 DE LA OEI}

\section{META GENERAL \\ META ESPECÍFICA}

\section{Primera:}

Reforzar y ampliar

la participación de la

sociedad en la acción educadora.

Segunda:

Lograr la

igualdad educativa y

superar toda forma de discriminación en la

educación.

1. Elevar la participación de los diferentes actores sociales y su coordinación en proyectos educativos: familias, universidades y organizaciones públicas y privadas, sobre todo de aquellas relacionadas con servicios de salud y promoción del desarrollo económico, social y cultural.

2. Garantizar el acceso y la permanencia de todos los niños en el sistema educativo mediante la puesta en marcha de programas de apoyo y desarrollo de las familias para favorecer la permanencia de sus hijos en la escuela.

3. Prestar apoyo especial a las minorías étnicas, poblaciones originarias y agrodescendientes, a las alumnas y alumnado que vive en zonas urbano marginales y en zonas rurales, para lograr la igualdad en la educación.

4. Garantizar una educación intercultural bilingüe de calidad a los alumnos pertenecientes a minorías étnicas y pueblos originarios.

5. Apoyo a la educación inclusiva del alumnado con necesidades educativas especiales mediante las adaptaciones y las ayudas precisas.

Tercera:

Aumentar la oferta de

la educación inicial y

potenciar su carácte educativo.

6. Aumentar la oferta de educación inicial para niños de

0 a 6 años.

7. Potenciar el carácter educativo de esta etapa y garantizar una formación suficiente de los educadores que se responsabilizan de ella.

\section{INTRODUCCIÓN}

docente.

Fuente: OEI (2010).
META GENERAL

Cuarta:

Universalizar la

educación primaria y

secundaria básica, y

ampliar el acceso a la

educación secundaria

superior.

Quinta:

Mejorar la calidad

de la educación y el

currículo escolar.

Sexta:

Favorecer la conexión

entre la educación y e empleo a través de la educación técnicoprofesional (ETP).

Séptima:

Ofrecer a todas las

personas oportunida-

des de educación a lo

largo de toda la vida.

Octava:
Fortalecer la profesión
docente.

Novena:

Ampliar el espacio

iberoamericano

del conocimiento y

fortalecer la investigación científica.

Décima:

Invertir más y mejor.

META ESPECÍFICA

8. Asegurar la escolarización de todos los niños en la educación primaria y en la educación secundaria básica en condiciones satisfactorias.

9. Incrementar la cantidad de jóvenes que finalizan la educación secundaria superior.

10. Mejorar el nivel de adquisición de las competencias básicas, y de los conocimientos fundamentales por parte de los alumnos.

11. Potenciar la educación en valores para una ciudadanía democrática activa, tanto en el currículo como en la organización y gestión de las escuelas.

12. Ofrecer un currículo que incorpore la lectura y el uso del computador en el proceso de enseñanza-aprendizaje, en el que la educación artística y la educación física tengan un papel relevante y estimule el interés por la ciencia, el arte y los deportes entre los alumnos.

13. Mejorar la dotación de bibliotecas y computadores en las escuelas.

14. Ampliar el número de escuelas de tiempo completo en la primaria.

15. Extender la evaluación de los centros escolares.

16. Mejorar y adaptar el diseño de la educación técnicoprofesional de acuerdo con las demandas laborales.

17. Aumentar y mejorar los niveles de inserción laboral en el sector formal de los jóvenes egresados de la educación técnico-profesional.

18. Garantizar el acceso a la educación a las personas jóvenes y adultas con mayores desventajas y necesidades.

19. Incrementar la participación de jóvenes y adultos en programas de formación continua presenciales y a distancia.

20. Mejorar la formación inicial del profesorado de primaria y de secundaria.

21. Favorecer la capacitación continua y el desarrollo de la carrera profesional docente.

22. Apoyar la creación de redes universitarias para las ofertas de posgrados, la movilidad de estudiantes e investigadores y la colaboración de investigadores iberoamericanos que trabajen fuera de la región.

23. Reformar la investigación científica y tecnológica y la innovación en la región.

24. Aumentar el esfuerzo económico de cada país para el logro de las Metas Educativas 2021.

25. Incrementar la solidaridad internacional con los países que manifiestan mayores dificultades.

Décima primera:

Evaluar el funcionamiento de los sistemas educativos y del proyecto "Metas Educativas 2021"

26. Fortalecer los sistemas de educación de cada uno de los países.

27. Asegurar el seguimiento y la evaluación del proyecto Metas Educativas 2021.

28. Fortalecer la participación de los distintos sectores sociales en el desarrollo y en la supervisión del proyecto Metas Educativas 2021. 
Brunner y Ferrada (2011), basados en las Metas 2021 de la OEI, destacan los objetivos de la dinamización del espacio iberoamericano del conocimiento, de la siguiente manera:

- Promover la cooperación orientada a la mejora continua de la calidad de la educación superior.

- Potenciar los esfuerzos que se vienen realizando para la cooperación de redes de cooperación e intercambio académico e investigador, como un medio eficaz para la construcción del Espacio Iberoamericano del Conocimiento.

- Apoyar a los organismos nacionales de ciencia y tecnología en la elaboración de políticas nacionales de ciencia, tecnología e innovación.

- Promover la alfabetización científica y estimular en los jóvenes la vocación por el estudio de la ciencia y la tecnología, a la vez que la independencia de juicio y un sentido de la responsabilidad crítica.

- Desarrollar y reforzar las capacidades científicas y tecnológicas de los países iberoamericanos y los recursos humanos de alta cualificación.

- Promover una agenda de ciencia y tecnología iberoamericana que responda a las demandas sociales de conocimiento y que favorezcan que favorezca la equidad y la cohesión social. (p.32)

Del mismo modo, los autores anteriores destacan que los objetivos citados, para efectos de cristalizarse, cuentan con un sistema de estrategias, las cuales se enuncian a continuación:

- Consolidar el Centro de Altos Estudios Universitarios (CAEU) de la OEI como instrumento de dinamización del Espacio Iberoamericano del Conocimiento.

- Potenciar el Observatorio Iberoamericano de la Ciencia, la Tecnología y la Sociedad como herramienta de seguimiento y evaluación de políticas de ciencia y educación superior en el marco del Espacio Iberoamericano del Conocimiento.

- Poner en marcha y consolidar un sistema de movilidad de estudiantes universitarios, con reconocimiento de estudios, así como de investigadores y docentes universitarios entre los países iberoamericanos.

- Crear espacios de interacción y colaboración entre universidades, centros de investigación, empresas y organizaciones sociales para la generación, trasmisión y transferencia del conocimiento, así como para generar demandas sociales.

- Fortalecer los equipos técnicos de los organismos sociales de ciencia y tecnología en materia de diseño, gestión y evaluación de políticas.

- Asesorar en el diseño y puesta en marcha de acciones orientadas a la promoción de vocaciones científicas en los estudiantes, en coordinación con las políticas educativas.

- Conformar redes tanto disciplinares como interdisciplinares de cooperación académica e investigadora en educación, ciencia y cultura.

- Establecer bajo la coordinación de la Secretaría General Iberoamericana (SEGIB), líneas de trabajo conjuntas con otros programas iberoamericanos de ciencia, tecnología e innovación (Brunner y Ferrada, 2011, p.32-33).

Si bien son ciertos los planteamientos que realiza la OEI, es importante además, identificar las inversiones económicas en la gestión del conocimiento, lo cual se verifica en la Figura 1, mostrada a continuación:

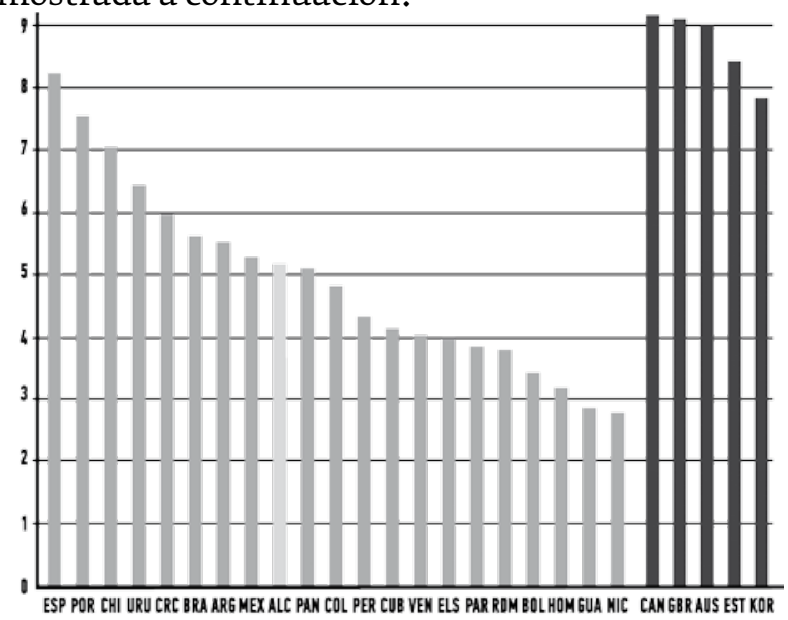

Figura 1. Índice de economía del conocimiento, 2009 Fuente: Bruner y Ferrara (2011).

Como se puede observar en la Figura 1, el Ecuador se encuentra entre los países que menor inversión realiza en la economía del conocimiento, encontrándose a la zaga de la mayoría de sus vecinos que conforman el MERCOSUR. Comparado con España, se encuentra en algo menos de la mitad de los valores que se invierten en conocimiento. Esto deja entrever que la política de desarrollo del país debe redireccionarse hacia inversiones 
en talento humano de forma estratégica, infraestructura multifuncional, equipamiento y gestión integral de la ciencia, tecnología, cultura e innovación del conocimiento.

Es necesario mirar al futuro en la educación superior. Atención especial merece la educación superior agropecuaria en el Ecuador, teniendo en cuenta que los cambios de fondo y forma requieren su secuencia ordenada de tiempo, esfuerzo y recursos invertidos, más aún, si se tienen en cuenta las demandas sociales y laborales recogidas en el Plan Nacional del Buen Vivir 2013-2017 (SENPLADES, 2014).

Se necesita que la academia asuma su rol protagónico, a través de los procesos de docencia, investigación y vinculación, poniéndolos al servicio de la sociedad. De esta forma lo expresa Bahillo y Campillo, (2015), cuando destacan que la Universidad en el siglo XXI, "debe proporcionar saberes contextualizados y aplicados a las necesidades de la sociedad actual y ser motor del cambio social en consonancia con las innovaciones que se producen en el contexto mundial y los grandes desafíos de la globalización" (p.105).

La universidad del siglo XXI se caracterizará por ser el crisol de permanente emergencia de conocimientos, nuevos saberes que tributen a una sociedad del buen vivir. Pero, ¿Qué debería entenderse con esta afirmación? Se empiezan a auscultar criterios institucionales como el de Houtart (2011), quien indica que el concepto del "Buen Vivir", proviene del planteamiento que hace la ONU, que cita: "El Bien Común de la Comunidad». En Ecuador se encuentra la Universidad Intercultural de las Nacionalidades y Pueblos Indígenas Amawtay Wasi (Casa de la Sabiduría), la que promueve como misión:

Contribuir en la formación de talentos humanos que prioricen una relación armónica entre la Madre Naturaleza y el Ser Humano sustentándose en el bien vivir comunitario como fundamento de la construcción del Estado Plurinacional y la Sociedad Intercultural (Indígenas, 2004, p.193).

En base a lo planteado anteriormente, al hablar de Buen Vivir y educación se toma en consideración lo planteado por el Estado Ecuatoriano en su Plan Nacional del Buen Vivir 2013-2017.

El postulado realizado por Ecuador, sobre la educación en el citado plan, es considerando la incursión en una sociedad democrática, que valora la participación ciudadana, que integra el colectivo social diverso, que busca

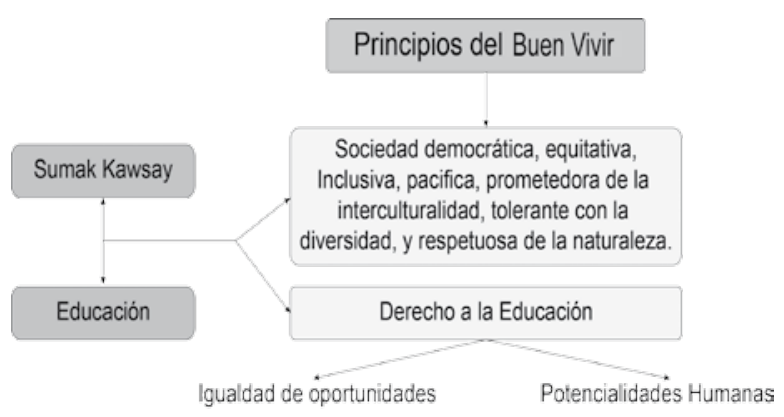

Figura 2. Plan Nacional del Buen Vivir del Ecuador y Educación. Fuente: SENPLADES (2014)

permanentemente la equidad, que promueve la pluriculturalidad y la inclusión, que se muestra respetuosa de la naturaleza, y toleran la diversidad. Constituye una propuesta pacífica, que garantiza los derechos a la igualdad de oportunidades y al desarrollo de las potencialidades humanas en base a la educación.

Al hablar de la formación universitaria en el siglo XXI, es necesario el abordaje desde la construcción social de nuevos conocimientos, como lo destaca Delors (2013), quien sugiere que la educación superior contemporánea debe abordarse desde una nueva concepción, la que permitiría que los individuos pudieran "descubrir, despertar e incrementar" las posibilidades de ser entes creativos para transformar su entorno. Continúa indicando el mismo autor, que en la actualidad ya no es suficiente el modelo educativo que enseña a aprender-haciendo, como lo desarrollan la mayor cantidad de instituciones académicas, sino que se requiere de una simultaneidad de ejes, que trabajándose sincrónicamente, den lugar al aprendizaje permanente (lifelong learning). Esto significa que todas las formas, medios, recursos, escenarios que sirvan para incrementar el acervo cultural y educativo, son parte del proceso de aprendizaje durante la vida del individuo.

A través de un secuenciamiento jerárquico (Matheson, 2014), apoyado de la tecnología merced a equipos electrónicos (computadoras, teléfonos y sus aplicaciones móviles), como lo proponen Nordin, Embi y Yunus (2010) y que, en función de las características, físicas, sociales y ambientales, se puedan conjuntar para que la propia persona sea capaz de desarrollar su nivel de conocimientos. Cuando vamos a un museo, una feria, un día de campo, una charla, un conversatorio, o cualquier otro tipo de evento académico, estamos siendo los propulsores de nuestro propio aprendizaje, el cual se puede 
movilizar en función de diversos agentes e influencias externas.

Las Tecnologías de la Información y Comunicación (TIC) han facilitado transformaciones en nuestra forma de vida, que de una u otra manera representan un cambio de época en el mundo contemporáneo.

Emergen un sinnúmero de transformaciones en nuestra comunidad, como lo referencian Ruz, Ramos y Martín (2012): "las estructuras de la realidad social, política y cultural. Nuestra sociedad ha pasado de la era industrial a la era del conocimiento y de la información" (p.71). Esto nos lleva a repensar en la necesidad de aprovechar tales oportunidades para nuestro beneficio y así lograr el buen vivir en la sociedad. Por ende, será importante que los modelos educativos y de formación, sean permeables a tales situaciones, haciendo eficiente el uso de recursos invertidos en la preparación de las personas para la vida. Una academia que valore estos planteamientos será aquella que establezca lineamientos estratégicos para aupar el desarrollo de la sociedad. Ejemplo de ello, lo cita Hernández (2014), cuando reporta que:

...la implementación de programas educativos virtuales, semiescolarizados y escolarizados que incorporan cursos en línea, así como de cualquier estrategia que a través del uso de las TIC permite ahorrar espacios físicos y la atención de un mayor número de estudiantes por profesor. (p.312)

Es una gran oportunidad para lasuniversidades, el diseñar y poner en marcha ofertas educativas con la convergencia de los medios disponibles, radio, televisión y todas las oportunidades que internet ofrece. De forma especial la Web 2.0, contribuye a potenciar el conocimiento entre los actores sociales. Lo expresado anteriormente implica un cambio de modelo educativo, lo que a criterio de Ferreiro (2010) supone la existencia de una evolución del proceso docente-formativo, suscitándose un "cambio de marcha" entre las formas en la que los docentes desarrollan su accionar. Visto lo citado por el autor anterior, es importante hacer una reflexión sobre el proceso que se ha venido desarrollando como parte de la docencia tradicional, que ha reafirmado el paradigma con el cual fue formada en el siglo pasado. Hoy, recorriendo la segunda mitad del segundo decenio del Siglo XXI, el siglo de innovación en ciencia y tecnología, el profesorado debe reflexionar sobre su actuación, sus prácticas y desempeño, para lograr la entrega a la sociedad de profesionales altamente competentes. La evolución de algunos de los cambios señalados anteriormente, se pueden apreciar en la Tabla 2.

TABLA 2. CAMBIOS REQUERIDOS EN EL PROCESO DE DOCENTEEDUCATIVO

\begin{tabular}{|ll|}
\hline ANTES & AHORA \\
\hline Aprendizaje lineal & Nuevos ambientes de aprendizaje \\
\hline Enseñanza memorística & Construcción social del conocimiento \\
\hline Aprendizaje competitivo & Aprendizaje cooperativo \\
\hline Enseñanza individualista & Interdependencia social \\
\hline Maestro/a trasmisor/a & Maestro/a mediador/a \\
\hline Aprendizaje escolar & $\begin{array}{l}\text { Aprendizaje para toda la vida (lifelong } \\
\text { learning) }\end{array}$ \\
\hline Aprendizaje por obligación & Placer por aprender \\
\hline $\begin{array}{l}\text { Aprendizaje centrado en el maestro } \\
\text { y contenido al aprendizaje }\end{array}$ & $\begin{array}{l}\text { Aprendizaje centrado en el desarrollo } \\
\text { personal y profesional del estudiante }\end{array}$ \\
\hline
\end{tabular}

Fuente: Ferreiro (2010).

Como se observa en la Tabla 2, se plantean los cambios en el abordaje del proceso docenteeducativo, los que se deben ir del escenario antiguo: Paradigma tradicional-vertical el maestro-"el que sabe» ("yo te enseño») y el alumno-"el que no sabe" ("tú aprendes») (Sáez, 2013, p. 30), hacia el paradigma alternativo o constructivista-colaborativo en donde "el desarrollo de un saber que tiene por matriz praxeológica la autosubversión como eje profesionalizante, donde la función del docente consiste en plantear al estudiante un desafío del que no pueda salir más que por sí mismo, usando su propia inteligencia” (Sáez, 2013, p.38).

Los procesos de innovación en las instituciones de educación superior toman su tiempo, como lo indica Tunnermann (2010), quien señala que se requiere de por lo menos 15 años en una universidad, mientras que en las empresas privadas se producen de forma más rápida. Ello nos lleva a reflexionar sobre la necesidad de sensibilizar a la academia, en virtud de que esta se encuentra formando profesionales que se desempeñarán en el mundo laboral, por ende, es necesario acogerse rápidamente a los cambios que demanda la sociedad contemporánea.

\section{MODELOS EDUCATIVOS DE VANGUARDIA PROSPECTIVA DE LA EDUCACIÓN SUPERIOR}

Mirar al futuro de la educación superior es necesario, en virtud de los innumerables cambios 
que se verifican en los entornos modernos. Se observa con atención lo que ocurre con el Espacio Europeo de Educación Superior (EEES), los nuevos abordajes propuestos por investigadores estadounidenses, el modelo planteado por el Mercado Común del Sur (MERCOSUR), y, el proceso que supone de adaptación de las ofertas educativas de grado y posgrado a los lineamientos que se establezcan. Se comienzan a analizar algunos de ellos. En la Figura 3, se diagrama el modelo Heutagogial o autodirigido, propuesto por Blaschke (2012), investigadora de las universidades de Oldenburg y Maryland, con el modelo lifelonglearning.

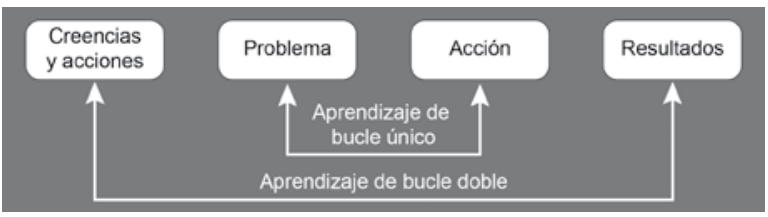

Figura 3. Modelo Heutagogical-Lifelong Learning. Fuente: Blaschke (2012).

La propuesta andragógica de la autora Blaschke, implica que el modelo Heutagogical, sea un proceso en el cual, el conocimiento se produce por una doble espiral (enlace/bucle), en primera instancia, entre - los resultados de aprendizaje y el problema estudiado - y en segundo lugar, los mismos resultados de aprendizaje, retroalimentando a las creencias y acciones del individuo y por ende sus prácticas, vivencias y experiencias. Esto representa una mayor implicación en el proceso de autoconducción (educación a distancia o por convergencia de medios) hacia el conocimiento por parte del adulto que es responsable de su autoeducación. El modelo Heutagogial o aprendizaje autodirigido (self-directed learning) resulta interesante como propuesta tanto para el adulto que inicia por primera vez sus estudios a nivel superior, como para el aprendizaje dirigido a docentes universitarios empleando la estrategia de enseñanza basada en proyectos. Con relación al enfoque anterior, los autores Cochrane, T., Antonczak, L., Gordon, A., Sissons, H., \&Withell, A. (2012) realizan una aportación y la denominan Learning and Teaching Development Fellows, -aprendiendo y desarrollando al docente-, mostrada a continuación en la Figura 4.

Las aportaciones que hacen los autores anteriores se articulan más adelante con la expresión de las Tecnologías Emergentes en el campo de la educación, las cuales llevan a la re-

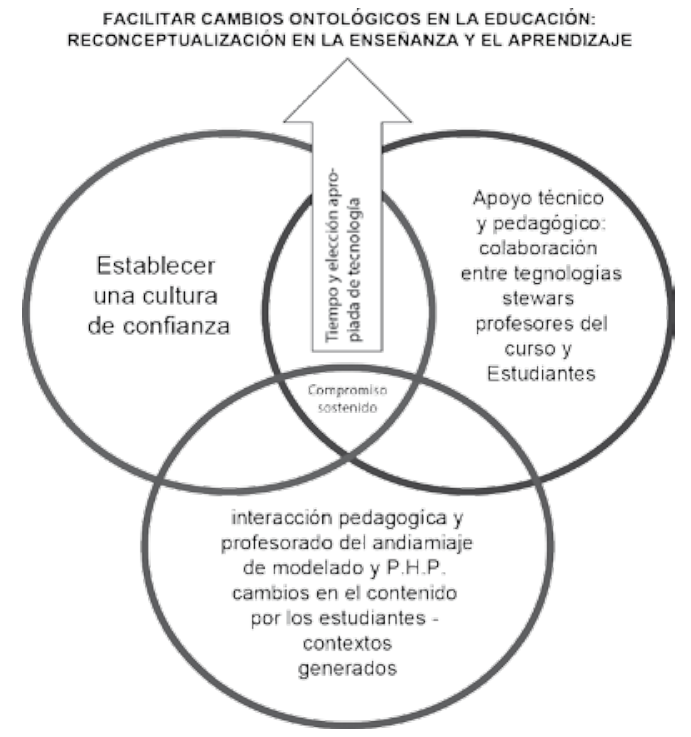

Figura 4. Fomento a los principales cambios ontológicos del modelo Heutagogial o de aprendizaje autodirigido. Fuente: Cochrane, et al (2012).

solución de algunos problemas de acceso a la información y facilitan la comunicación para un aprendizaje más eficiente. Sáez (2012) hace un señalamiento importante respecto al tema del aprendizaje basado en proyectos utilizando las tecnologías emergentes, indicando que fundamentándose en la investigación, y asistido por la profesionalización del profesorado, se logran integrar elementos que hacen más amenas las clases. La experiencia comentada por el autor indica que esta estrategia de trabajo o modelo propuesto tendría un abordaje multifactorial, al convertirse en una estrategia de intervención derivada de la ciencia y la tecnología.

La Enseñanza Basada en Proyectos (EBP) es una oportunidad para trabajar el aprendizaje de las ciencias y representa un abordaje que requiere de experiencia del docente y de un conocimiento profundo de su especialidad profesional, ya que la EBP es además, una estrategia educativa que:

Implica que el docente desarrolle nuevas habilidades y destrezas, ya que se verá sacudido por la misma problemática que el estudiante enfrentará, corregida y aumentada, principalmente porque habrá de asumir una metodología a la que, en general, no está acostumbrado (Benítez y García, 2013, p.24).

Este planteamiento resulta novedoso principalmente para el estudio de las llamadas "ciencias duras", por lo que serviría de apoyo para el estudio de las matemáticas, la física, la quí- 
mica, la biología y sus ciencias derivadas y las aplicaciones para la enseñanza en las carreras agropecuarias de la Universisdad Católica de Santiago de Guayaquil (UCSG).

La innovación educativa es, a criterio de López (2012), un abordaje flexible, una forma de mediar entre el conocimiento y el estudiante en diferentes contextos (aula, unidad, institución, comunidad, país). Consecuentemente, también incluye su proyección hacia el mundo contemporáneo, donde el protagonismo lo tiene quien accede, sobre todo, si se vinculan el uso de las TIC. De esta forma, se pueden acceder a propuestas que hagan más eficientes los procesos formativos.

El uso de las TIC en la Educación Superior permite el desarrollo de proyectos innovadores que posibiliten los cambios de actitudes, pensamientos, culturas contenidos, modelos de trabajo y sentidos de las prácticas pedagógicas (Noriega, Morán y García, 2014, p.145).

El empleo de las TIC junto a la EBP, se convierte en una herramienta que facilitará los procesos de formación en las ciencias agropecuarias, $y$ en otras ciencias, ya que permiten al estudiante y su docente, hacer abordajes innovadores que generen cambios trascendentales en la calidad educativa. Hablar de innovación en la educación superior es referirse a los modelos existentes en los países desarrollados; por ejemplo el modelo europeo implementado hacia los inicios del nuevo siglo. Por ello, para complementar el análisis del presente trabajo en el apartado siguiente se hará un recuento por el EEES y su modelo de competencias profesionales.

\section{EL ESPACIO EUROPEO DE EDUCACIÓN SUPERIOR}

La Declaración de Bolonia, firmada en junio 19 de 1999 crea el EEES, el cual se estructura con la intención de fortalecer la calidad en la educación (Vicente, 2008), en los 30 países suscriptores (Nieva Fenoll, 2015). Otro de los objetivos era afrontar problemas comunes en cuanto a las ofertas académicas para atender la empleabilidad y la diversificación de la educación privada y los acuerdos comunes para atenderlos (Salaburu, Haug y Mora, 2011). Para Curiel (2010), existen seis acuerdos básicos que funcionan como "caballo de batalla" del Acuerdo de Bolonia y que se convierten en los ejes del EEES:
- Adopción de un sistema de titulaciones fácilmente reconocibles y comparables.

- Adopción de un sistema de titulaciones basado esencialmente en dos ciclos: grado y posgrado.

- Establecimiento de un sistema común de créditos.

- Promoción de la movilidad.

- Promoción de la cooperación europea en el control de la calidad.

- Promoción de las dimensiones europeas en la enseñanza superior (p.24).

La Declaración de Bolonia a criterio de Salaburu, Haug y Mora (2011) se genera con objetivos puntuales, a saber:

- Crear el EEES, para potenciar la empleabilidad de los graduados y la movilidad entre las titulaciones, mejorando la calidad de la oferta educativa en Europa.

- Estandarizaciones entre las instituciones de educación superior (IES), de un sistema de créditos transferibles a nivel europeo European Credits Transfer Systems (ECTS) respecto de las titulaciones de: Grados: entre 180 y 240 ECTS en un tiempo no menor de tres años y no mayor a cuatro años de escolaridad; Másteres: entre 90 a 120 ECTS, con extensiones de año y medio a dos años de estudios y con excepciones especiales de 60 ECTS; Doctorados: sin precisar números de ECTS, con tiempos que superen los tres años.

- Los mecanismos para facilitar la movilidad de los miembros de la comunidad universitaria europea, estudiantes, docentes, investigadores e inclusive, personal administrativo. (p.26-29)

Sobre la base de lo indicado se han integrado en la Tabla 3, detalles de los momentos más importantes del proceso de implantación del modelo educativo europeo.

Lo evidenciado por el modelo del EEES sirve de referente al sistema ecuatoriano, en virtud de una necesaria armonización de títulos profesionales. Esto ha sido realizado por el Consejo de Educación Superior del Ecuador (CES), al expedir en el año 2014, el Reglamento de Armonización de la Nomenclatura de Títulos Profesionales y Grados Académicos que confieren las Instituciones de Educación Superior Codificado. 
tABLA 3. MOMENTOS DESTACADOS DEL MODELO EDUCATIVO EUROPEO.

\begin{tabular}{|c|c|}
\hline HITO IMPORTANTE & ACCIÓN DEFINIDA \\
\hline Declaración de Sorbona, 1998 & $\begin{array}{l}\text { Prelineamientos para Bolonia, sin plan } \\
\text { de acción. } \\
\text { La empleabilidad de los graduados. } \\
\text { Programa de cooperación ERASMUS. } \\
\text { La expansión de la oferta universitaria. } \\
\text { Atractividad y retención del modelo } \\
\text { educativo europeo ante los rankings } \\
\text { mundiales. } \\
\text { Eficiencia en la inversión. }\end{array}$ \\
\hline $\begin{array}{l}\text { Asociación Europea de Agencias de } \\
\text { la Calidad ENQA, } 1988\end{array}$ & $\begin{array}{l}\text { Normativa de acreditación y } \\
\text { aseguramiento de la calidad en la } \\
\text { educación superior. }\end{array}$ \\
\hline Declaración de Bolonia, 1999 & $\begin{array}{l}\text { Definición de EEES. } \\
\text { Sistema ECTS. } \\
\text { Movilidad de participantes. }\end{array}$ \\
\hline Estrategia de Lisboa, 2000 & $\begin{array}{l}\text { Hasta } 2010,15 \text { estados de la UE } \\
\text { se convertirían en potencia a nivel } \\
\text { educativo mundial. }\end{array}$ \\
\hline Proyecto Tunning, 2001 y 2003 & $\begin{array}{l}\text { Definición de las competencias } \\
\text { profesionales en las titulaciones. }\end{array}$ \\
\hline Convenio Cultural Europeo, & 47 países miembros. \\
\hline Declaración de Berlin, 2003 & $\begin{array}{l}\text { Lifelong Learning (Comunicado de } \\
\text { Praga, 2001). }\end{array}$ \\
\hline $\begin{array}{l}\text { National Qualification Frameworks, } \\
\text { NQF }\end{array}$ & $\begin{array}{l}\text { Posterior a la adhesión al proceso de } \\
\text { Bolonia. }\end{array}$ \\
\hline $\begin{array}{l}\text { Informe Trends 1, presentado en } \\
\text { Bolonia, } 2009\end{array}$ & $\begin{array}{l}\text { Acuerdos intergubernamentales para } \\
\text { normalizar titulaciones } \\
\text { Facilitar intercambio de información } \\
\text { para retroalimentar ofertas } \\
\text { académicas. }\end{array}$ \\
\hline
\end{tabular}

Fuente: Salaburu, Haug y Mora (2011). Adaptado por los autores.

Con similares lineamientos a los del EEES, el Consejo de Evaluación, Acreditación y Aseguramiento de la Calidad de la Educación Superior (CEAACES) propuso en el 2013, el modelo genérico para la evaluación de las carreras presenciales y semipresenciales universitarias en el Ecuador. El proceso se ha iniciado con la carrera de Medicina y Ciencias de la Salud, a continuación la de Jurisprudencia y Educación, y luego de 2016 con las de Ingenierías.

EL MODELO DE FORMACIÓN POR COMPETENCIAS Conocido como Tuning (Tuning Educational Structures in Europe), el sistema de competencias implantado desde el año 2000 en el EEES, en que un grupo de universidades europeas coincidieron en la estructuración de un proyecto piloto en el que se definieron las competencias (García-Manso y Martín-Cabello, 2014). Entre las competencias se identifican dos agrupaciones principales: generales y específicas.
Según Torra, Del Corral, Pérez, Triadó i Ivern, Pagés, Valderrama Vallés y Tena (2012), las competencias generales, se definen como transferibles comunes a todo perfil profesional y las cuales, a su vez, se reorganizan en competencias instrumentales, interpersonales y sistémicas. Estas competencias son necesarias para el desempeño de la vida en general aunque, en función de la profesión en que se den, se requerirá de una mayor intensidad en unas que en otras. (p.24)

La terminología de competencias generales implica, que un conjunto de habilidades, destrezas y conocimientos, junto con los valores integrados por una persona, un estudiante, o un profesional, se pongan de manifiesto al desarrollar una actividad. Estas competencias podrán ser similares o comunes en las diferentes especialidades y profesiones. Su grado de transferibilidad estará en dependencia de la práctica docente, la cual estará en estrecha relación con las competencias que este profesorado haya desarrollado previamente. A continuación se muestra en la Figura 5, la derivación que referencia de las competencias generales.

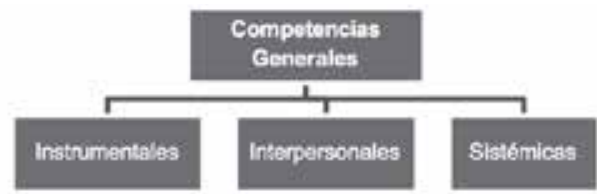

Figura 5: Competencias Generales Fuente: Torra et al (2012).

Como se observa en la Figura 5, la derivación de las competencias generales obedece al nivel de transversalidad en todas las profesiones. No constituye una excepción la profesión docente. Se definen y enlistan a continuación las apreciaciones de algunos autores sobre el tema.

Las competencias generales-instrumentales son definidas como "aquellas que se dirigen a la adquisición de conocimientos cognoscitivos, habilidades metodológicas, tecnológicas y/o lingüísticas» (González y Martínez, 2012, p.205).

- Análisis y Síntesis

- Organización y planificación

- Conocimientos generales básicos

- Conocimientos básicos de la profesión

- Comunicación oral y escrita (lengua propia)

- Conocimiento segunda lengua

- Manejo básico de la informática

- Gestión de la información

- Resolución de problemas

- Toma de decisiones 
Las competencias generales expuestas, sirven de referencia para la construcción de un programa de fortalecimiento y mejora permanente de las competencias del profesorado universitario, en especial en las carreras agropecuarias de la UCSG. Cabe destacar, las competencias generales-instrumentales para el desarrollo de las capacidades de análisis y síntesis de los volúmenes de información que le llegan al docente desde las diferentes fuentes; el dominio que tiene el docente para la planificación de su trabajo integrando los conocimientos actualizados de la profesión en sinergia con la experiencia del profesor innovador, trabajando con las herramientas informáticas y demostrando el manejo de la lengua materna y una segunda lengua, preparando a sus estudiantes en el proceso de toma de decisiones, a partir de la enseñanza basada en problemas.

Las competencias generales-interpersonales en base al EEES son definidas como aquellas que "hacen relación a las habilidades de tipo individual y social, se relacionan con la inteligencia emocional: capacidad crítica y autocrítica, trabajo en equipo, habilidades interpersonales, capacidad de trabajo interdisciplinar, capacidad de comunicación con otras áreas, apreciar la diversidad y multiculturalidad, capacidad de trabajo en contexto internacional, compromiso ético» (González y Martínez, 2012, p.205).

Un programa de formación del profesorado altamente competente, que integre las competencias generales-interpersonales, aprovechará el modelo educativo de corte humanístico que tienela UCSG, alincluir materias como Introducción al Pensamiento Crítico, Ética Profesional, Humanismo Integral, Estudios Contemporáneos, entre otras. Estas materias desarrollan en los miembros de la comunidad universitaria la capacidad de crítica y autocrítica y potencia el trabajo en equipos multidisciplinarios, transdisciplinarios, intercarreras (interdisciplinarias). De igual forma, propicia el despliegue de su actividad de forma ética y responsable, con criterios de integralidad y multiculturalidad, con proyección innovadora y futurista en el contexto nacional e internacional.

Por su parte las competencias generales-sistémicas, basadas en el EEES son definidas como aquellas que corresponden a capacidades que dan visión global, holística, de conjunto y que sirven para organizar y gestionar las acciones:

- Aplicar los conocimientos a la práctica

- Habilidades de investigación
- Capacidad de aprender (aprender a aprender)

- Adaptación a nuevas situaciones

- Creatividad (generar nuevas ideas)

- Liderazgo

- Conocimiento de otras culturas

- Capacidad de trabajo autónomo

- Diseño y gestión de proyectos

- Iniciativa y espíritu emprendedor

- Preocupación por la calidad

- Motivación de logro (González y Martínez, 2012, p.205).

Un profesorado acreditado como competente en las carreras agropecuarias de la UCSG, luego de cursar un programa de fortalecimiento de capacidades, desarrolla sus competencias generales-sistémicas en el contexto de la práctica universitaria (práctica docente) para la generación de nuevos, creativos, innovadores y mejores conocimientos a través de los diferentes niveles de investigación. Fomenta entre los participantes de los grupos de trabajo, el liderazgo asertivo, con la capacidad de aprender de forma permanente y significativa, sustentando la calidad del nivel académico y la productividad en favor de la ciencia y la tecnología. A partir del diseño y gestión de proyectos deben llegar a sentir satisfacción por el logro de resultados y la puesta en marcha del espíritu emprendedor, en un marco de respeto y reconocimiento autonómico de la interculturalidad.

Una vez definidas las competencias generales, se detallan las competencias específicas, las cuales son definidas como "aquellas que son propias de un perfil profesional, dan identidad y consistencia a cualquier profesión" (Torra et al, 2012, p.24).

Las competencias específicas, se asociarán a la práctica profesional de cada especialidad. Es decir, un profesional del campo amplio de la Agricultura, Silvicultura, Pesca y Veterinaria (Clasificación Internacional Normalizada de la Educación-UNESCO), tendrá su propio grupo de competencias específicas propias para su desarrollo profesional, diferenciándose de las de otras especialidades profesionales en diferentes campos del saber. Claro está, que en los casos de las competencias para la rama de la Ingeniería, existirán algunas competencias específicas comunes con otros graduados de alguna de las ramas que la integran. Las competencias específicas tienen también, al igual que las anteriores, su derivación, las que se muestran en la Figura 6. 


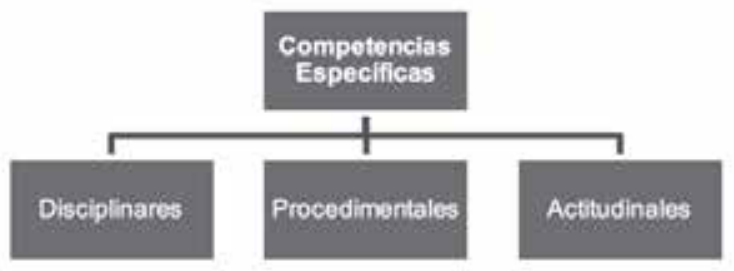

Figura 6. Competencias Específicas.

Nota Fuente: Curiel (2010).

Según lo apreciado en la Figura 6 y lo planteado en el proyecto Tuning (2001), Conzález, Wagenaar, y Beneitone (2004) señalan que la derivación que se muestra de las competencias específicas, se relaciona a las vinculadas a la profesión (Ortega, 2010); así como también, el conjuntar capacidades de movilizar los recursos académicos especializados en cada una de las profesiones, y que los docentes universitarios que contribuimos en la formación de las distintas "profesiones", debemos tener, evidenciar y fomentar entre los estudiantes y son disciplinares (Saber), procedimentales (Saber hacer), y actitudinales (Ser) (Curiel, 2010). Las competencias específicas o profesionales, (Galvis, 2008), se deben ir adaptando a las características pedagógicas requeridas en cada oferta académica (carrera), modalidad en que ésta se desarrolla e institución educativa que la oferta.

Un profesorado altamente competente con relación a la competencias específicas-disciplinares o transversales, como lo señala Díaz Barriga (2010), son esenciales a lo largo de toda la vida del profesional y en otros aspectos de la vida. Por ejemplo, el saber leer, interpretar y comprender lo leído, sirve al individuo en todas las facetas de la vida. En el caso de los docentes de las carreras agropecuarias de la UCSG, una competencia específica-disciplinar sería el conocimiento sobre el abordaje agroproductivo con el modelo de agricultura orgánica que protege el ambiente, siendo el nuevo esquema que lidera el paradigma de cambio en la actividad productiva agropecuaria.

El desarrollo de las competencias específicasprocedimentales o metodológicas (Minguet y Solís, 2009), integrarían el conjunto de estrategias, técnicas, metodologías y proceso para la toma de decisiones, al igual que la puesta en práctica (o en marcha) de acciones específicas. Para caracterizar una competencia específica procedimental o metodológica de los docentes de las carreras agropecuarias de la UCSG, se puede enunciar la aplicación del método científico para los procesos investigativos y de generación de nuevos conocimientos. Esto, desde el abordaje, el planteamiento de la hipótesis o las preguntas de investigación, al igual que el desarrollo y manejo de la investigación; así mismo, la puesta en práctica de la matriz de marco lógico para el planteamiento de proyectos de toda índole.

Los docentes con competencias específicasactitudinales desarrollan aptitudes y actitudes que se adquieren durante el proceso de formación profesional y que derivan en el ejercicio ético y moral, al desempeñar su accionar como profesional (Mena, Carvajal, Téllez, Barranco, Gallego y Bellido, 2009).

El desarrollo de la competencia específica actitudinal en el profesorado de las carreras agropecuarias de la UCSG, se pone de manifiesto al momento en que los docentes respetan y promueven normas éticas de desempeño profesional. Por ejemplo, al guardar sigilosamente acuerdos de convivencia interna en la comunidad universitaria y fuera de ella, respetando los códigos del ejercicio profesional de cada especialidad, sobre todo, en aquella que tiene que ver con el bien común. Que el profesorado contemporáneo en la educación superior sea altamente competente, es la preocupación permanente de la IES, ya que los modelos de acreditación de la educación superior, hacen especial énfasis en la "práctica docente" y cómo toma cuerpo en el proceso de enseñanza-aprendizaje. Por ende, se vuelven prioritarios los programas de formación del profesorado para el desarrollo, apropiación y puesta en curso de tales desempeños.

Formar profesores para que desarrollen competencias profesionales no será tarea fácil, especialmente si deseamos que de esta formación emanen unas prácticas docentes de calidad, innovadoras, contextualizadas, apropiadas a cada caso y, cómo no, previamente razonadas (Mas Torrelló, 2011, p.205).

El criterio de Mas Torrelló, está argumentando la necesidad de que el desempeño del docente de educación superior, se haga con la más alta calidad, en base a los estándares previstos. Está indicando que se considere una práctica innovadora en cuanto a la aplicación de las modernas tecnologías y sobre todo, que el proceso que desarrollarían los profesores universitarios, tribute al criterio de pertinencia y/o contextuali- 
zación que los diferentes escenarios del ejercicio profesional requieran. Preparar profesionales para las demandas sociales y laborales, que sean producto de un diseño curricular apropiado y adecuado las necesidades de un quehacer profesional. En ello subyace lo que indica Zabalza (2012) con relación a la formación del profesorado para atender las competencias profesionales.

Nos llevará tiempo cambiar el chip de muchos profesores universitarios para hacerles entender que son formadores y que deben orientar su trabajo académico hacia la mejora global de sus estudiantes (Zabalza, 2012, p.75).

En todo caso, el modelo propiciado por el EEES para las competencias profesionales es un buen referente ya que "El sistema universitario público español es un sistema homogéneo con una calidad media aceptable a nivel internacional» (Pérez-Esparrells y Casani, 2012, p.335), y que serviría de baremo comparativo para el establecimiento de un modelo adecuado y adaptado a las realidades de la situación ecuatoriana. Por lo que se coincide con Zabalza, cuando dice que se "abre una oportunidad excelente para mejorar la docencia de nuestras universidades" (Zabalza, 2012, p.94).

En el continente americano se han gestado varias iniciativas de normatividad sobre el tema de las competencias. Por ello es importante mencionar el trabajo que ha desarrollado el modelo MERCOSUR Educativo, el cual se analiza en detalles en el siguiente apartado.

\section{EL SECTOR EDUCATIVO MERCOSUR}

El modelo MERCOSUR Educativo, o Sector Educativo MERCOSUR (SEM) se crea en el año 1991 por convergencia de los países fundadores (Argentina, Brasil, Uruguay, Paraguay) que contaban con un sistema educativo de nivel superior organizado (De Donini, 2011). En la actualidad hay otros países asociados, entre los que pueden mencionarse Chile (1996), Bolivia (1998), Perú (2003), Venezuela, Ecuador y Colombia (2004) y posteriormente Guyana y Surinam. Como inspectores de la evolución del bloque se encuentran México y Nueva Zelanda. Los principios corporativos del SEM son:

- Visión: Ser un espacio regional donde se brinda y garantiza una educación con equidad y calidad, caracterizado por el conocimiento recíproco, la intercultura- lidad, el respeto a la diversidad, la cooperación solidaria, con valores compartidos que contribuyan al mejoramiento y democratización de los sistemas educativos de la región y a generar condiciones favorables para la paz, mediante el desarrollo social, económico y humano sustentable.

- Misión: conformar un espacio educativo común, a través de la concertación de políticas que articulen la educación con el proceso de integración del MERCOSUR, estimulando la movilidad, el intercambio y la formación de una identidad y ciudadanía regional, con el objeto de lograr una educación de calidad para todos, con atención especial a los sectores más vulnerables en un proceso de desarrollo con justicia social y respeto a la diversidad cultural de los pueblos de la región (De Donini, 2011, p.62).

Sobre los principios corporativos del SEM, se puede comentar que tanto la visión como la misión demuestran que dicho estamento se estructura como un modelo educativo integrador, con una perspectiva clara que privilegia la calidad en los procesos de formación, en un marco de equidad, para el buen vivir, potenciando el desarrollo sostenido de los países miembros. Es importante seguir de cerca la evolución del modelo educativo propuesto por el SEM. Se torna interesante para la investigación, el conocer los principios orientadores y sus objetivos estratégicos. Los principios orientadores del MERCOSUR EDUCATIVO (2015) son: "confianza, respeto y consenso, solidaridad, cooperación, impacto, difusión y visibilidad, gradualidad, diálogo e interacción" (p.10), los cuales se muestran en concordancia a la declaratoria de la UNESCO sobre la educación, sus articulados y lineamientos en el marco de acción para atender al derecho mundial de la humanidad, del acceso a la educación. Entre los objetivos estratégicos del SEM, según del MERCOSUR (2015), se cuentan los siguientes:

- Contribuir a la integración regional acordando y ejecutando políticas educativas que promuevan una ciudadanía regional, una cultura de paz y el respeto a la democracia, a los derechos humanos y al medio ambiente;

- Promover la educación de calidad para todos como factor de inclusión social, de desarrollo humano y productivo; 
- Promover la cooperación solidaria y el intercambio, para mejorar los sistemas educativos;

- Impulsar y fortalecer programas de movilidad de estudiantes, pasantes, docentes, investigadores, gestores, directivos y profesionales; $y$

- Concertar políticas que articulen la educación como el proceso de integración del MERCOSUR. (p.13)

Revisando los objetivos estratégicos del SEM, se pueden identificar algunos mecanismos de interacción que las universidades ecuatorianas en materia de integración regional pueden implementar. Entre ellos destacan, el Informe de unificación, homologación y equiparación de las carreras de Ingeniería Agropecuaria trabajo realizado en nuestro país por el Consejo Nacional de Facultades de Ciencias Agropecuarias y Afines-CONFCA (2010) desde hace 43 años en el área agropecuaria y ambiental; lo propuesto por el CEAACES, en materia de educación de calidad para todos, que coincide con las políticas del Plan Nacional del Buen Vivir (PNVB) (SENPLADES, 2014). Estas políticas promueven los lineamientos del bienestar de la sociedad en el marco de la integración sur-sur, para que los participantes de la comunidad universitaria tengan las posibilidades de la movilidad, para que exista una retroalimentación positiva y se mejoren los sistemas educativos.

\section{SISTEMA DE CRÉDITOS Y ACREDITACIÓN DEL SISTEMA EDUCATIVO} MERCOSUR

Luego del año 2000, en que se le recomendó a los países del MERCOSUR, la adopción de un modelo común que brinde flexibilidad a la vez que promueva el desarrollo de redes académicas y facilite la movilidad de profesores y estudiantes, en el año 2001 se generaron acuerdos para el establecimiento de políticas de homologación de estudios, acreditación, movilidad estudiantil, reconocimiento de estudios parciales, y la implementación de un sistema de créditos académicos con sus respectivas equivalencias (Restrepo, 2005).

Desde susinicios, el MERCOSUR ha avanzado en el desarrollo de un modelo de acreditación de carreras universitarias, que ha sido el promotor de importantes transformaciones en la educación superior de los países (Hermo y Verguer, 2011). Este modelo de acreditación comenzó a partir del 2002 con la carrera de Agronomía, siendo acreditada con posterioridad a partir del
2005. Luego continuaron con Ingenierías en el campo amplio de la Agricultura, Silvicultura, Pesca y Medicina, para llegar a la actualidad a una modelación similar a la del EEES para cada una de las profesiones.

Los espacios comunes entre EEES y SEM Son numerosas las aproximaciones entre ambos modelos, como lo reseña Hermo y Verguer (2011):

La Red Iberoamericana para la Acreditación de la Calidad de la Educación Superior (RIACES) Buenos Aires, 2003, que es una asociación de agencias y organismos de evaluación y acreditación de la calidad de la educación superior constituida para promover entre los países iberoamericanos la cooperación y el intercambio en la materia. La ALCUE, Espacio Común de Enseñanza Superior, en el 2002 para facilitar el intercambio del conocimiento, la transferencia de tecnología y la circulación de estudiantes, profesores, investigadores y personal administrativo. (p.10)

Lagoria (2013), al referirse a la aproximación de los dos modelos (EEES y SEM) señala que "pensar en convergencia, integración y espacios comunes de educación superior nos remite a considerar la existencia de elementos con características compatibles y capaces de unificarse en un único sistema» (p.71). Esto nos lleva a pensar que es posible una equiparación curricular en muchas de las profesiones y entre ellas, las agropecuarias.

En el año 2004, se crea el Proyecto Tuning para la América Latina, por lo que como guía de trabajo servirían las competencias profesionales genéricas de la Ingeniería establecidas, las cuales son detalladas a continuación:

1. Capacidad de abstracción, análisis y síntesis.

2. Capacidad de aplicar los conocimientos en la práctica.

3. Capacidad para organizar y planificar el tiempo.

4. Conocimientos sobre el área de estudio y la profesión.

5. Responsabilidad social y compromiso ciudadano.

6. Capacidad de comunicación oral y escrita.

7. Capacidad de comunicación en un segundo idioma. 
8. Habilidades en el uso de las tecnologías de la información y de la comunicación.

9. Capacidad de investigación.

10. Capacidad de aprender y actualizarse permanentemente.

11. Habilidades para buscar, procesar y analizar información desde fuentes diversas.

12. Capacidad crítica y autocrítica.

13. Capacidad para actuar en nuevas situaciones.

14. Capacidad creativa.

15. Capacidad para identificar, plantear y resolver problemas.

16. Capacidad para tomar decisiones.

17. Capacidad de trabajo en equipo.

18. Habilidades interpersonales.

19. Capacidad de motivar y conducir hacia metas comunes.

20. Compromiso con la preservación del medio ambiente.

21. Compromiso con su medio socio-cultural.

22. Valoración y respeto por la diversidad y multiculturalidad.

23. Habilidad para trabajar en contextos internacionales.

24. Habilidad para trabajar en forma autónoma.

25. Capacidad para formular y gestionar proyectos.

26. Compromiso ético.

27. Compromiso con la calidad (Palma Lama, Miñan, Ubillús y Ríos Carmenado, 2011, p. 2561).

Una vez revisadas las competencias generales para la rama de la Ingeniería propuesta por el modelo Tuning y el EEES para América Latina, es evidente que el listado de 27 competencias, faculta de forma transversal a las diferentes especialidades de la Ingeniería. De igual forma, sustentan el desempeño de un profesional moderno, capaz de lograr un desempeño eficiente en su entorno laboral, atendiendo a los desafíos que el mundo contemporáneo le demanda. Al analizar estas competencias generales de la Ingeniería, propuestas por el modelo Tuning, se conforma la tendencia de un perfil profesional del docente universitario que trabaje en su desarrollo al interior del aula de clases. Es necesario conocer lo que se espera del profesorado ante el planteamiento realizado con relación a las competencias generales y cuáles serían las competencias a su vez, del profesor de educación superior.
Sobre las competencias genéricas o transversales del docente de educación superior, Morales y Cabrera (2012) toman el trabajo de Beneitone (2007) sobre la clasificación de las competencias genéricas o transversales del docente de educación superior y establecen las siguientes competencias instrumentales:

- Capacidad de análisis y síntesis,

- Capacidad de organizar y planificar,

- Conocimientos generales básicos,

- Conocimientos básicos de la profesión,

- Comunicación oral y escrita en la propia lengua,

- Conocimiento de una segunda lengua,

- Habilidades básicas de manejo del ordenador,

- Habilidades de gestión de la información (habilidad para buscar y analizar información proveniente de fuentes diversas),

- Resolución de problemas,

- Toma de decisiones. (p.83-84)

Estas competencias instrumentales del profesorado universitario le servirán para desarrollar la investigación y la generación de nuevo conocimiento. Para el trabajo relacionado con la gestión académica las empleará con el fin de organizar de la mejor manera su accionar, al igual que en el proceso de toma de decisiones y en el discernimiento entre las alternativas para las soluciones a situaciones-problema. De igual forma, le ayudarán en la mejora de su comunicación con los estudiantes, los pares académicos y la comunidad en general.

Son señaladas como competencias interpersonales por Morales y Cabrera (2012):

- Capacidad crítica y autocrítica.

- Trabajo en equipo.

- Habilidades interpersonales.

- Capacidad de trabajar en un equipo interdiscipinar.

- Capacidad para comunicarse con expertos de otras áreas.

- Apreciación de la diversidad y multiculturalidad.

- Habilidad de trabajar en un contexto internacional.

- Compromiso ético. (p.83-84)

Un docente que desarrolle sus competencias interpersonales, será un individuo reconocido por: su calidez humana, su accionar reflexivo que lo 
mejora de forma permanente, su habilidad para la interacción multidisciplinaria y el trabajo en equipo. Además será distinguido por ser respetuoso de la diversidad y sensible ante la necesidad de integración multicultural de la comunidad universitaria. Se detallan entre las principales competencias sistémicas las siguientes:

- Capacidad de aplicar los conocimientos en la práctica,

- Habilidades de investigación,

- Capacidad de aprender,

- Capacidad para adaptarse a nuevas situaciones,

- Capacidad para generar nuevas ideas (creatividad),

- Liderazgo,

- Conocimiento de culturas y costumbres de otros países,

- Habilidad para trabajar de forma autónoma,

- Diseño y gestión de proyectos,

- Iniciativa y espíritu emprendedor,

- Preocupación por la calidad,

- Motivación de logro (Morales y Cabrera, 2012, p.83-84).

En el momento en que un profesor universitario ponga de manifiesto sus competencias sistémicas se estarán alcanzando un conjunto de metas. Se obtendrán colectivos humanos que logren sustentar redes y sociedades del conocimiento; se retroalimenten de forma permanente en la búsqueda de nuevos saberes, integrando vivencias y experiencias de otras realidades que sean proactivas y precursoras del cambio generacional, planteando propuestas de desarrollo creativas e innovadoras; $y$ fomenten, mantengan y potencien permanentemente la calidad y la excelencia educativa.

Sobre la base de las competencias generales del profesorado universitario, se destaca la competencia sistémica de diseño y gestión de proyectos, las que sirven a la institución para propiciar su desarrollo a partir del planteamiento de sus ideas. Aprovechando la Estrategia Maestra de Internacionalización del Ministerio de Educación Superior de Cuba, Medero, Rodríguez, Guerra y Álvarez, (2012), realizaron un trabajo de investigación en la Universidad de Cienfuegos, sobre el perfil de competencias del profesor universitario para la gestión de proyectos internacionales. Estas fueron agrupadas en tres unidades de competencias, las cuales se detallan a continuación:
Unidad de Competencia No. 1: presentar la propuesta de Proyecto ante el Grupo de la Línea Científica Universitaria. El profesor Universitario será capaz de:

- Defender la propuesta de Proyecto ante el Consejo Científico de la Facultad.

- Acceder a la convocatoria del Financista a través de la Presentación del Perfil del Proyecto.

- Realizar posibles ajustes y modificaciones por sugerencias del financista. (p.5)

Esta competencia les sirve a los docentes universitarios para argumentar sus ideas y estrategias de desarrollo ante un claustro especializado. Deben transferirla a sus estudiantes para que ellos logren de forma práctica, eficiente y efectiva, argumentar sus planteamientos, siendo respetuosos de la crítica de terceros.

Unidad de Competencia No. 2: definir con carácter terminal los objetivos, establecer la planificación necesaria de resultados y actividades, elaborar el presupuesto, establecer mecanismos de control y de información. El Profesor Universitario será capaz de:

- Elaborar el Contrato Económico de conjunto con el Financista y los clientes.

- Obtener la firma del Rector como representante legal de la Entidad Ejecutora.

- Obtener la firma del Financista y del Cliente,

- Obtener la firma de los Términos de Referencia.

- Inscribir el Proyecto y nombrar su Sustituto como Jefe de Proyecto.

- Elaborar documentos para los Controles Internos de la UCF en correspondencia con los informes parciales.

- Presentar los resultados del proyecto en sesiones científicas o seminarios de su departamento en el marco del Crupo de Expertos de la Línea Científica y ante el Consejo Científico de la Facultad (Medero et al, 2012, p.5).

La competencia de planificación de actividades que el profesor universitario desarrolle, facilitará su gestión para la integración de los diferentes elementos que coadyuvan a un proceso de enseñanza-aprendizaje de alta calidad.

Unidad de Competencia No. 3: realizar los informes parciales establecidos por el Financista 
sobre la marcha de los proyectos. El profesor universitario será capaz de:

- Proponer a la dirección de la unidad administrativa correspondiente la evaluación anual del personal que participa en el proyecto.

- Autorizar a otros miembros del equipo el uso del fondo según las reglas establecidas para el uso del financiamiento.

- Rendir la información actualizada del proyecto en las auditorías que se realicen.

- Aplicar el tipo de evaluación acorde a la actividad" (Medero et al, 2012, p.5).

La competencia del docente de educación superior para la comunicación eficiente, se pone de manifiesto para la transferibilidad de información entre los distintos actores de un proceso; ello ayudará a que sus estudiantes logren destrezas al momento de socializar sus ideas y propuestas.

Ayuga, González y Grande (2010) reportan sobre las competencias genéricas y específicas de la ingeniería para la adaptación al EEES y las señalan como:

\section{COMPETENCIAS GENÉRICAS DE LA INGENIERÍA (I)}

G1. "Responsabilidad moral y profesional.

G2. Juicio crítico y creatividad.

G3. Comunicarse efectivamente.

G4. Analizar, plantear y solucionar problemas reales en ingeniería.

G5. Relacionarse y trabajar en equipo.

G6. Liderar equipos y tomar decisiones con autonomía.

G7. Fluidez para expresarse en diferentes idiomas.

G8. Fomentar el desarrollo propio y la mejora continua, adaptándose al entorno.

G9. Reconocer la incertidumbre del conocimiento y actitud innovadora.

G10. Formar a otros profesionales” (p. 9-10).

Así mismo, los autores anteriores citaron las competencias específicas de la ingeniería y de competencias específicas de la rama forestal, mismas que se detallan a continuación:

COMPETENCIAS ESPECÍFICAS DE LA INGENIERÍA (I)

1. Obtener e interpretar información de campo.

2. Utilizar las nuevas tecnologías de la información.
3. Identificar, evaluar e implementar las tecnologías más apropiadas para su contexto.

4. Crear, innovar y emprender para contribuir al desarrollo tecnológico.

5. Evaluar el impacto ambiental y social de su actividad.

6. Administrar recursos materiales y humanos, así como diferentes equipos (Ayuga, González y Grande, 2010, p.9-10).

\section{COMPETENCIAS GENERALES Y PROFESIONALES EN ÁREA AGROPECUARIA DEL SEM}

En materia de competencias profesionales en el área de la agricultura, es necesario mencionar el caso del Mecanismo Experimental de Acreditación de las Carreras (MEXA) ${ }^{1}$, generado por el Foro de Decanos de Agronomía del MERCOSUR desde 1998 (posteriormente sería Foro Regional de Facultades de Agronomía del MERCOSUR). En base a reuniones sucesivas de las autoridades académicas han logrado acuerdos para armonizar el tema de las competencias profesionales, la movilidad, la internacionalización, el posgrado, la investigación y la vinculación con la comunidad (Panambi, 2009). A partir del trabajo realizado por el MEXA, en Argentina se ha avanzado en el tema de la determinación y definición de los estándares de acreditación regional en la Agronomía, por ende, el tema de las competencias profesionales (Nosiglia, Zaba, Mulle y Polzella, 2013).

"La competencia ha de identificar aquello que necesita cualquier persona para dar respuesta a los problemas con los que se enfrentará a lo largo de su vida" (Ruso, 2013, p.89). Al referirse en su trabajo sobre las capacidades y competencias del extensionista agropecuario y forestal en la globalización, donde hace un detalle de las funciones para ser competitivo como profesional de extensión agropecuaria y forestal, las mismas que se identifican como: 1 . Aprender a prender; 2. Capacidad para comunicarse; 3. Capacidad para convivir; 4. Capacidad para tomar decisio-

Entre 1999 y 2002, representantes de los países miembros y asociados del MERCOSUR desarrollaron perfiles y criterios de evaluación para tres carreras (Medicina, Ingeniería y Agronomía). Establecieron normas y orientaciones para los procedimientos de acreditación y promovieron la formación y entrenamiento de evaluadores. En el 2002 se aprobó el resultado de este trabajo y se puso en marcha la aplicación del Mecanismo Experimental de Acreditación MERCOSUR (MEXA) para las tres carreras en los países miembros (Molina, 2013). 
nes; 5. Capacidad para organizarse; y, 6. Capacidad para gestionar iniciativas de desarrollo personal y colectivo (Russo, 2013, p.88).

Si bien es cierto que el tema de las competencias profesionales se encuentra íntimamente relacionado con las funciones del profesional, es aún, un tópico en continua evaluación, atendiendo a la complejidad sistémica y grado de evolución de la nueva ruralidad existente en nuestros tiempos.

Ayuga-Téllez, González-García y GrandeOrtiz, (2010), reportan las competencias de los profesionales en la rama forestal, las cuales son detalladas a continuación:

COMPETENCIAS ESPECÍFICAS DE LA RAMA FORESTAL (F):

1. Aplicar conocimientos de las ciencias básicas de la ingeniería forestal.

2. Concebir, analizar, proyectar y diseñar obras de ingeniería forestal.

3. Planificar y programar obras y servicios propios de la ingeniería forestal.

4. Realizar, supervisar e inspeccionar obras de ingeniería forestal.

5. Modelizar y simular sistemas naturales y procesos de ingeniería forestal.

6. Tomar decisiones y gestionar los recursos naturales. w

7. Encontrar soluciones que contribuyan a la sostenibilidad de los recursos naturales.

8. Interactuar con grupos multidisciplinares para dar soluciones integrales al medio ambiente"(p. 9-10).
Como se puede observar, las competencias específicas de la Ingeniería Forestal se muestran íntimamente orientadas al desempeño profesional: su objeto de estudio, los sistemas forestales y el ámbito de trabajo en el que el profesional ejerce su competencia. Es importante seguir sumando nuevos modelos de competencias del profesional agropecuario tales como las del Ingeniero Agrónomo y Médico Veterinario. Esto permitirá tener elementos de juicio que faciliten plantear las nuevas competencias de los profesionales que formará la UCSG con visión al año 2020 y la articulación respectiva que deban tener los docentes universitarios con sus prácticas habituales para el desarrollo de tales competencias. Un referente importante se constituye desde hace varios años atrás, en el llamado modelo Accreditation Board for Engineering and Technology (ABET), el cual se emplea en Estados Unidos para acreditar programas de Ingeniería.

\section{CRITERIO DE ACREDITACIÓN SOBRE LOS RESULTADOS DE APRENDIZAJE - ACCREDITATION BOARD FOR ENGINEERING AND TECHNOLOGY}

ABET es un modelo vigente en los Estados Unidos con el cual se verifica la acreditación de IES con carreras o programas de ingeniería, tecnología, computación y ciencia aplicada. Para ello ha generado criterios con los cuales mide el desempeño de los graduados de un programa de tercer nivel en alguna de las ramas de la ingeniería (ABET, 2015). Para comprender el funcionamiento del modelo analítico del llamado EC2000, el cual es

\begin{tabular}{|c|c|c|}
\hline CAMBIOS DEL PROGRAMA & EXPERIENCIAS DE LOS ESTUDIANTES & \\
\hline $\begin{array}{l}\text { Currículum e instrucción } \\
\text { Conocimientos básicos } \\
\text { Contenidos y estándares } \\
\text { Habilidades comunicativas } \\
\text { Habilidades de proyectos } \\
\text { Aprendizaje activo } \\
\text { Pedagogía tradicional } \\
\text { Cultura de Facultad } \\
\text { Evaluación para la mejora } \\
\text { Desarrollo profesional } \\
\text { Las políticas y practicas } \\
\text { Enfasis en la enseñanza } \\
\text { en recompensas } \\
\text { Cambios en los recursos }\end{array}$ & $\begin{array}{l}\text { En sus clases } \\
\text { Claridad instructor } \\
\text { Aprendizajes colaborativos } \\
\text { Instructor interactivo y } \\
\text { retroalimentación } \\
\text { Programa abiertos a ideas } \\
\text { y personas } \\
\text { Fuera de la clase } \\
\text { Interaprendizaje / educación } \\
\text { Cooperativa } \\
\text { Estudiar en el extranjero } \\
\text { Viaje internacional } \\
\text { Diseño de competencia } \\
\text { Capítulo sociedad } \\
\text { Profesional } \\
\text { Programa de diversidad } \\
\text { del clima en el aula }\end{array}$ & $\begin{array}{c}\downarrow \\
\text { Resultados de } \\
\text { aprendizaje de } \\
\text { la A - K } \\
\text { A }\end{array}$ \\
\hline
\end{tabular}

Figura 7. Modelo analítico para vincular EC2000 con los resultados de aprendizaje de la A a la K. Fuente: ABET ( 2006) 
un documento que muestra el impacto que han tenido los resultados de aprendizaje de la "a" a la «k», en el sistema de acreditación ABET. Esto puede ser apreciado en la Figura 7.

En el Ecuador, tanto las universidades de categoría A como la Escuela Superior Politécnica del Litoral (ESPOL), han gestionado la acreditación de las carreras de Ingeniería Mecánica, Ingeniería en Petróleos, Ingeniería Naval, Ingeniería en Electricidad e Ingeniería en Computación. Estas han recibido ya sus respectivas credenciales (Proyecto ABET-ESPOL, 2015). Una vez revisado el modelo analítico de $\mathrm{ABET}$, ahora se muestran en la Tabla 4, las competencias para los programas de ciencias.

\section{tabla 4. COMPETENCIAS abet para los programas DE CIENCIAS}

\section{CRITERIOS DE ACREDITACIÓN ABET EN BASE A LOS RESULTADOS DE} APRENDIZAJE EN PROGRAMAS DE CIENCIAS

(a) la capacidad de aplicar los conocimientos de matemáticas, ciencias y ciencias aplicadas.

(b) la capacidad para diseñar y realizar experimentos, así como analizar e interpretar los datos.

(c) la capacidad de formular o diseñar un sistema, proceso o programa para satisfacer las necesidades deseadas.

(d) la capacidad de funcionar en equipos multidisciplinarios

(e) una capacidad de identificar y resolver problemas de ciencias aplicadas.

(f) una comprensión de la responsabilidad profesional y ética.

( $g$ ) la capacidad de comunicarse de manera efectiva.

(h)la amplia educación necesaria para entender el impacto de las soluciones en un contexto global y social.

(i) el reconocimiento de la necesidad y la capacidad de participar en el aprendizaje de por vida.

(j) el conocimiento de temas contemporáneos.

( $k$ ) la capacidad de utilizar las técnicas, habilidades y herramientas científicas y técnicas modernas necesarias para la práctica profesional.

Fuente: Engineering Change. A Study of de Impact of EC2000. Executive Summary

Estos criterios de acreditación de los programas de ciencias, basados en el análisis de los resultados de aprendizaje (los cuales medirían las competencias profesionales de los graduados), son evaluados desde varios abordajes, perspectivas y percepciones de los diferentes actores sociales. Uno de ellos es la empresa (empleadores) que contrata a los profesionales, por lo que en la Figura 8, se muestran los ratios que los empleadores les dan a los resultados de aprendizaje de la "a" a la "k» del modelo ABET para la Ingeniería, al momento de contratación de nuevos colaboradores. El detalle se muestra a continuación.

En base a los criterios ABET para las carreras de Ingeniería, el Massachusetts Institute of Technology (MIT) de Estados Unidos, generó su propuesta Conceive, Desing, Implement and Operate (CDIO): Concebir, Diseñar, Implementar y Operar un proceso o un sistema (Palma, Miñan y Ríos, 2011), priorizando las ciencias básicas y la técnica, brindando los entornos de aprendizaje necesarios para que los estudiantes vayan desarrollando sus habilidades prácticas. Éste sistema ha sido empleado inicialmente en el MIT y en universidades suecas.La iniciativa CDIO tiene tres grandes objetivos generales: dominar un conocimiento profundo de técnicas fundamentales, liderazgo en la creación y operación de nuevos productos, procesos y sistemas y entender la importancia y el impacto estratégico de la investigación y el desarrollo tecnológico en la sociedad (Palma, Miñan y Ríos, 2011, p.2557).

Sobre lo que mencionan, los autores Palma, Miñan y Ríos (2011), se revisa ahora el "syllabus CDIO", propuesto por el MIT, que deriva en primer y segundo orden a sus objetivos. La Tabla 5 muestra el detalle.

\section{tABLA 5. DETALleS DEL SYLLABUS CDIO DEL MIT SOBRE LAS COMPETENCIAS DE LOS GRADUADOS}

\section{OBJETIVOS DE PRIMER Y SEGUNDO ORDEN DEL SYLLABUS CDIO}

1. Conocimiento técnico y el razonamiento.

1.1 Conocimiento de las ciencias fundamentales

1.2 Conocimientos básicos de la ingeniería.

1.3 Conocimientos fundamentales de la ingeniería avanzada

2. Habilidades y atributos personales y profesionales.

2.1 Razonamiento ingenieril y resolución de problemas.

2.2 Experimentación y descubrimiento del conocimiento.

2.3 Pensamiento sistémico.

2.4 Habilidades y actitudes personales.

2.5 Habilidades y actitudes profesionales.

OB JETIVOS DE PRIMER Y SEGUNDO ORDEN DEL SYLLABUS CDIO

3. Habilidades interpersonales: trabajo en equipo y la comunicación.

3.1 El trabajo en equipo.

3.2 Comunicación.

3.3 La comunicación en lenguas extranjeras

4. Concebir, diseñar, implementar y operar sistemas en la empresa y el contexto social.

4.1 Contexto social y externo.

4.2 Empresa y contexto empresarial.

4.3 Concibiendo los sistemas de ingeniería.

4.4 Proyectos.

4.5 Implementación.

4.6 Funcionamiento. 


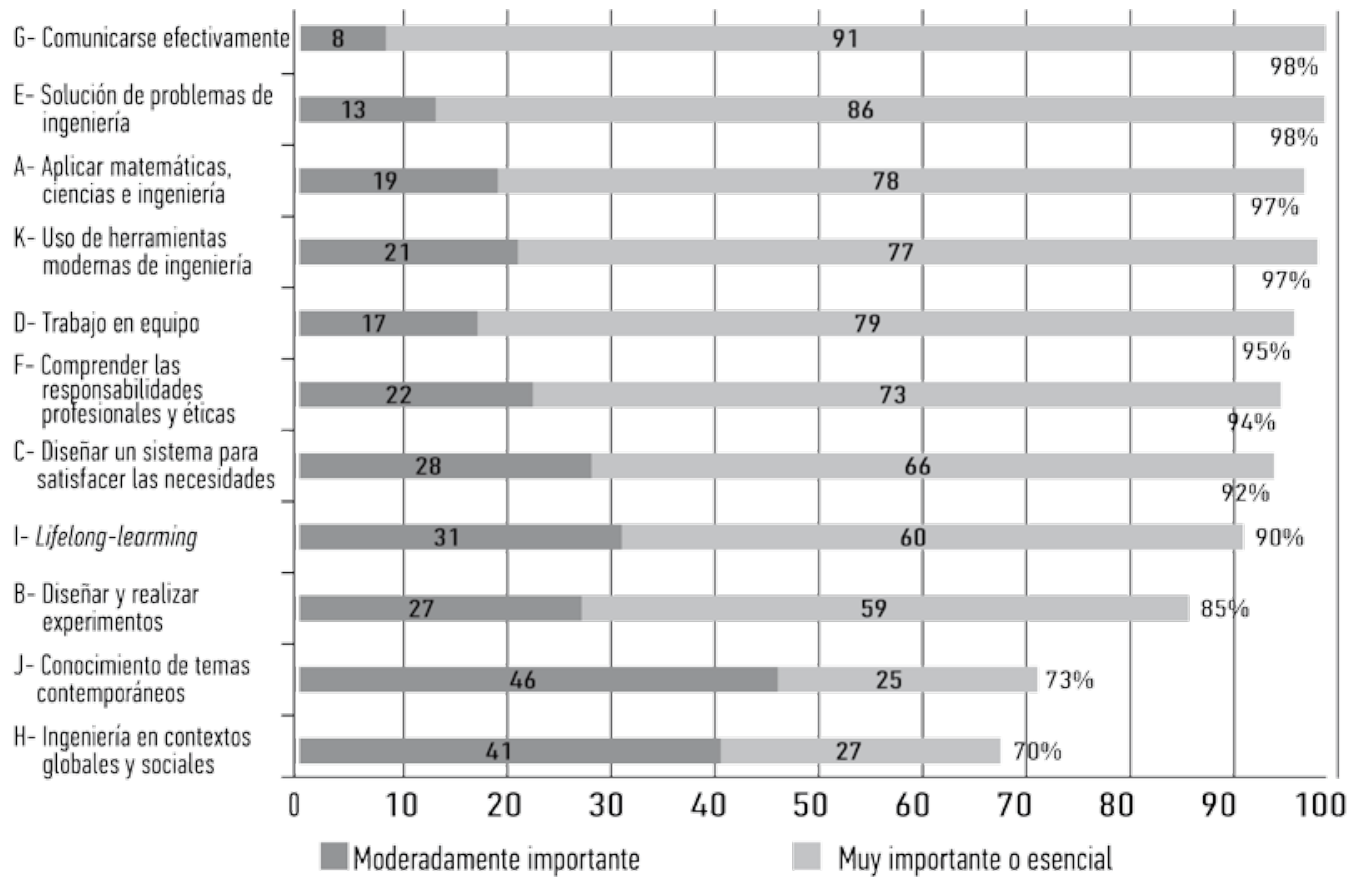

Figura 8. Calificaciones que los empleadores dan en orden de importancia a los resultados de aprendizaje de la A a la K en el modelo ABET. Fuente: ABET (2006).

Los contextos modernos en los que los profesionales agropecuarios deben desempeñarse, demandan de su praxis profesional la eficiente comunicación y la resolución de problemas como las dos más altas competencias de los profesionales (ABET, 2006), por lo que las IES deben trabajar en el desarrollo de tales habilidades entre sus estudiantes.

Los docentes universitarios no serán la excepción a la norma dictada por el mundo empresarial, por lo que se deben aplicar metodologías interactivas para el logro de dichas competencias. Una de ellas es el aprendizaje basado en proyectos, el cual se orienta a la resolución de problemas en base a la propuesta de ideas innovadores que, junto a habilidades de comunicación derivan en la correcta gestión de proyectos, haciendo al profesional más competitivo.

El aprendizaje basado en proyectos (ABP), como lo reportan Palma, Miñán y Ríos (2011) tiene como fundamentación el syllabus CDIO, requiriendo un mayor compromiso de parte del estudiantado para apropiarse del conocimiento. Esto sin dejar de lado, la responsabilidad de los docentes en gestionar los entornos de aprendizaje necesarios para este nuevo abordaje del proceso docente-educativo.

Para el caso de las carreras agropecuarias de la UCSG, el que tanto su profesores, como sus estudiantes y graduados desarrollen la competencia a partir de la ABP, ayudará desa- rrollar las competencias genéricas (Guerrero, La Rosa y Palma, 2014) y se constituiría en un factor altamente competitivo y comparativo en el mundo profesional. Aquí subyace una diferencia significativa en el modelo del profesional que se visiona para el horizonte 2020 propuesto por la Agenda Agroalimentaria ${ }^{2}$ que sirve de insumo para el desarrollo del presente trabajo. Profesionales agropecuarios ecuatorianos que sepan gestionar proyectos en todas sus etapas: idear, planificar, implementar y operar proyectos productivos, socio-productivos, socioambientales y articularse a proyectos sociales o de cualquier índole, definirán el impacto que tendrán en entorno contemporáneo y la ABP servirá de ejemplo para el resto de asignaturas de la Facultad (Guerrero, La Rosa y Palma, 2014). Por ello, es necesario implicarse en la investigación intracátedra y modelo de investigación-acción; así como identificarse con los modelos internacionales de generación de proyectos y de medición de las competencias de los estudiantes y graduados en ésta actividad para tener elementos comparativos y de juicio.

La International Project Management Association (IPMA) y la Asociación Española de Ingeniería de Proyectos (AEIPRO) a través del OCDP

2 Documento diseñado por el equipo investigador para la orientación del trabajo de necesidades de formación del profesorado. 
(Organismo Certificador de Dirección de Proyectos), seleccionan las competencias en tres ámbitos: técnicas, de comportamiento y contextual” (Palma, Miñan y Ríos, 2011, p.2559).

Es importante para el presente trabajo de investigación conocer los elementos de competencia de la IPMA, para los graduados de una carrera de Ingeniería, por lo que son mostrados a continuación en la Tabla 7.

\section{TABLA 7. ELEMENTOS DE COMPETENCIA DE IPMA}

\section{COMPETENCIAS TÉCNICAS}

1.01 Éxito en la dirección de 1.11 Tiempo y fases del proyecto proyectos

\begin{tabular}{|c|c|}
\hline 1.02 Partes interesadas & 1.12 Recursos \\
\hline $\begin{array}{l}1.03 \text { Requisitos y objetivos del } \\
\text { proyecto }\end{array}$ & 1.13 Costos y financiación \\
\hline 1.04 Riesgo y oportunidad & 1.14 Aprovisionamiento y contratos \\
\hline 1.05 Calidad & 1.15 Cambios \\
\hline 1.06 Organización del proyecto & 1.16 Control e informes \\
\hline 1.07 Trabajo en equipo & 1.17 Documentación e información \\
\hline 1.08 Resolución de problemas & 1.18 Comunicación \\
\hline 1.09 Estructuras del proyecto & 1.19 Lanzamiento \\
\hline 1.10. Alcance y entregables & 1.20 Cierre \\
\hline \multicolumn{2}{|c|}{ 2. COMPETENCIAS DE COMPORTAMIENTO } \\
\hline 2.01 Liderazgo & 2.09 Eficiencia \\
\hline 2.02 Compromiso y motivación & 2.10 Consulta \\
\hline 2.03 Autocontrol & 2.11 Negociación \\
\hline 2.04 Confianza en sí mismo & 2.12 Conflictos y crisis \\
\hline 2.05 Relajación & 2.13 Fiabilidad \\
\hline 2.06 Actitud abierta & 2.14 Apreciación de valores \\
\hline 2.07 Creatividad & 2.15 Ética \\
\hline \multicolumn{2}{|l|}{2.08 Orientación a resultados } \\
\hline \multicolumn{2}{|l|}{ 3. COMPETENCIAS CONTEXTUALES } \\
\hline 3.01 Orientación a proyectos & $\begin{array}{l}3.07 \text { Sistemas, productos y } \\
\text { tecnología }\end{array}$ \\
\hline 3.02 Orientación a programas & 3.08 Dirección de personal \\
\hline 3.03 Orientación a carteras & $\begin{array}{l}3.09 \text { Seguridad, higiene y medio } \\
\text { ambiente }\end{array}$ \\
\hline $\begin{array}{l}3.04 \text { Implantación de proyectos, } \\
\text { programas y carteras }\end{array}$ & 3.10 Finanzas \\
\hline 3.05 Organizaciones permanentes & 3.11 Legal \\
\hline 3.06 Negocio & \\
\hline
\end{tabular}

Fuente: IPMA (2006).

El Ojo de la Competencia de IPMA, mostrado en la Figura 9, se interpreta como: «la integración de todos los elementos de la gestión de proyectos como se ve a través de los ojos del director del proyecto en la evaluación de una situación específica. El ojo representa la claridad y visión" (IPMA, 2006, p. 2 ).

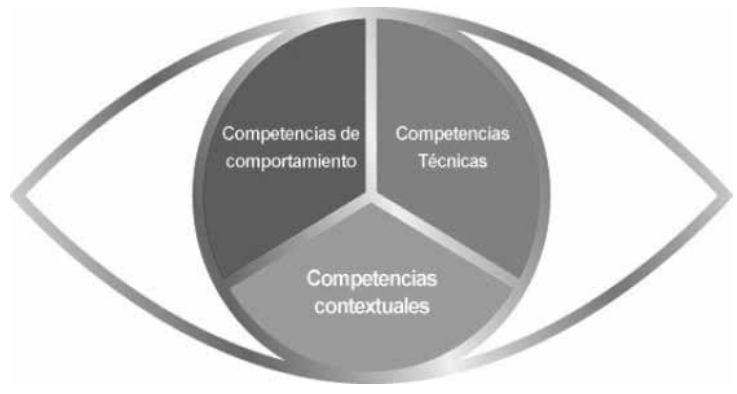

Figura 9. 0jo de la Competencia de IPMA. Fuente: IPMA (2006).

Un programa de formación de los docentes altamente competentes en las carreras agropecuarias de la UCSG, debe integrar la Enseñanza Basada en proyectos EBP con una doble finalidad, y que lo profesores/as se apropien de lo necesario para: i) preparar proyectos a nivel nacional e internacional para el desarrollo de la investigación, la innovación y el desarrollo de la ciencia y la tecnología, y, ii) trabajen junto a sus estudiantes en la generación de ideas para transformar las realidades de su entorno actual y futuro. Un claustro docente altamente competente, será el pilar fundamental para el desarrollo institucional, generando planes, programas y proyectos encaminados a sustentar el ecodesarrollo ordenado del país. Para ello se tienen que buscar alternativas educacionales que permitan llegar a un mayor volumen de personas de forma simultánea. Por ello se revisa ahora la modalidad de educación a distancia, semipresencial y en convergencia de medios.

\section{LA VIRTUALIZACIÓN DE LA EDUCACIÓN SUPERIOR: LA EDUCACIÓN SEMIPRESENCIAL Y EN CONVERGENCIA DE MEDIOS}

Se entiende por Virtualización de la Educación, al proceso que permite la integración de forma simultánea de la comunicación a través de los medios electrónicos que principalmente giran alrededor del uso de la INTERNET como motor principal de trabajo. La virtualización es "representar de electrónicamente y de forma numérica digital objetos y procesos que encontramos en el mundo real» (Silvio, 2010, p.28). Todo ello, con la finalidad de compartir, transferir, facilitar y acompañar al individuo para que se apropie del conocimiento y sea capaz de construir con él, elementos necesarios para su desempeño profesional futuro.

Es posible entonces construir y operar aulas virtuales (como espacios de enseñanza y aprendizaje), laboratorio virtuales (como espacios 
de investigación) y bibliotecas virtuales (como espacios para la conservación y el intercambio de informaciones y conocimiento que sirven de soporte a la enseñanza, el aprendizaje y la investigación (Silvio, 2010, p.28).

Para Imbernón, Silva y Guzmán (2011) indican que la virtualización de la educación es una excelente alternativa de trabajo para llegar con los conocimientos hasta lugares remotos, venciendo las barreras de la distancia, la infraestructura, y la temporalidad, ya que las características propias de la modalidad permite el acceso a quienes se encuentran distantes de los centros educativos y/o disponen de tiempos distintos para dedicarlo a su formación personal. Las estrategias de trabajo dentro de la virtualización de la educación que son de mayor difusión se denominan e-learning (electronicslearnig - aprendizaje usando las TIC) (Morgado, 2010:24), y b-learning (blendedlearning - formación combinada o aprendizaje mixto) (Morgado, 2010:27).

COMPETENCIAS DEL DOCENTE UNIVERSITARIO ANTE LA VIRTUALIZACIÓN DE LA EDUCACIÓN

El nuevo entorno educativo que ofrece la internet para la virtualización de la educación demanda que el docente universitario se encuentre al día con el desarrollo de sus competencias profesionales para su desempeño en este nuevo ambiente de la educación superior.

Rodríguez (2010), señala que el docente universitario ante la virtualización debe desarrollar las siguientes funciones basadas en "i. Desarrollador de contenidos propios, ii. Trabajo interdisciplinario, iii. Utilización de la red como canal de comunicación, iv. Asumir las redes como espacio cooperativo y de comunicación, y v. Usar las redes como espacio de trabajo" (p.4). En base a lo planteado anteriormente, el propio Rodríguez, (2010), realiza una propuesta de competencias del profesorado que interviene en la educación virtual con sus respectivos indicadores de logro, lo cual se muestra en la Tabla 8, expuesta a continuación:

Es destacable que los docentes universitarios reciban la formación necesaria para abordar los procesos en este ambiente emergente de la educación, el cual demanda permanente preparación y actualización y sobre todo del profesorado, requiere el reconocimiento de que nos encontramos ante una nueva época en el quehacer educativo. El contexto actual requiere de docentes altamente competentes, sobre todo para el manejo de la tecnología de la información y la comunicación, y de programas de
TABLA 8. PROPUESTA DE COMPETENCIAS DEL DOCENTE EDUCADOR VIRTUAL

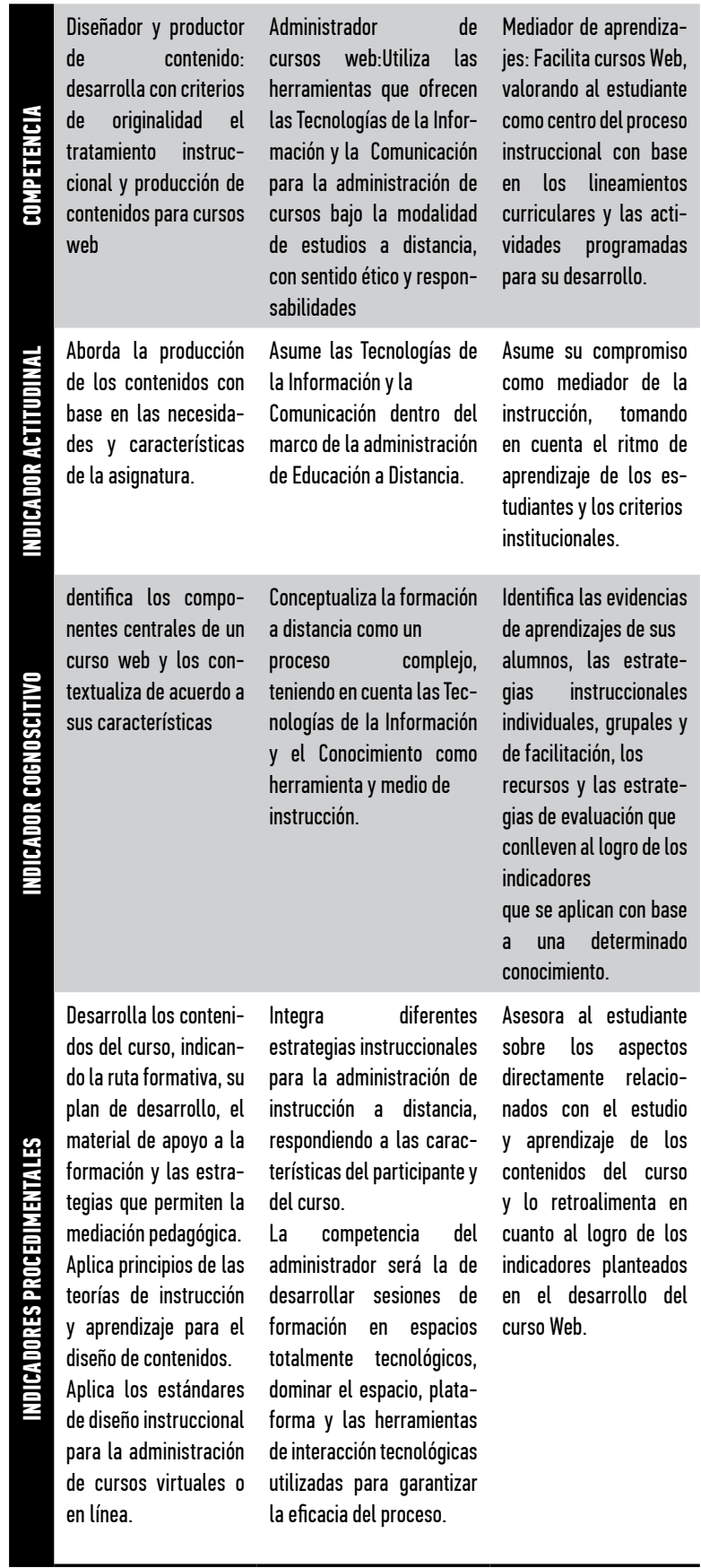

Fuente: (Rodríguez, 2010). Adaptado por los autores.

formación que "se puedan realizar por caminos diferentes, en función de concepciones sobre la educación y el papel del docente como facilitador de aprendizajes significativos para los estudiantes" (Imbernón-Muñoz, Silva-García, y Guzmán-Valenzuela, 2011, p.112).

CONCLUSIONES

Los modelos educativos imperantes en el entorno contemporáneo ayudan a los gestores académicos que trabajan con la prospectiva para el diseño y mejora permanente de sus programas 
educativos, a fin de que sean conducidos por la excelencia académica y el reconocimiento de la sociedad y la respectiva acreditación de dichas alternativas.

La implementación de tales modelos educativos de vanguardia implican que la unidad académica se encuentre preparada en infraestructura y con un claustro docente imbuido de una mística de trabajo y anhelos de prepararse de forma permanente y pertinente en temas relacionados con el mejoramiento de su desempeño profesional, sobre la base de una buena relación con sus estudiantes.

Esto les permitirá retroalimentar su práctica docente con las nuevas experiencias y los saberes actualizados con la puesta en práctica de las estrategias formativas innovadoras, favoreciendo el desarrollo de nuevas competencias en el alumnado.

Cuando se integran las competencias profesionales genéricas y específicas en los currículos universitarios, se genera la posibilidad de que los futuros graduados cuenten con los elementos que les permitan atender las necesidades de las demandas sociales y laborales que se muestran como retos permanentes de los profesionistas. Más aún, si sus relaciones se dan en el campo agropecuario, el cual requiere de innovaciones para abaratar los estudios y llegar a un mayor auditorio optimizando los recursos.

Es destacable el hecho de que la virtualización de la educación es una alternativa que permite llegar a un mayor volumen de personas, integrándolas a los procesos formativos en todos los niveles. Para el caso de las carreras agropecuarias de la UCSG, es un reto importante que se visiona con futuro, sobre todo, para abaratar costos de las ofertas de grado. Esto, posibilita atender a los habitantes de las zonas rurales que se encuentren ávidos de tener una formación universitaria que lo ayude a mejorar sus condiciones de vida y por sobre todo, proyectar su relevo generacional con potencialidades de cambio en los sistemas imperantes de la producción agropecuaria del Ecuador.

Para complementar las estrategias de trabajo, a partir de la virtualización de la educación se puede emplear las Tecnologías Emergentes que cada día cobran una mayor difusión, aceptación y uso en los entornos familiares, sociales y laborales del contexto contemporáneo. Será importante seguir investigando para construir un apartado que conjunte las principales tecnologías que basadas en las TIC que se encuentran a disposición de los docentes universitarios para integrarlos a los procesos de enseñanzaaprendizaje, recreando entornos de aprendizaje y facilitando la mediación entre el conocimiento y los estudiantes, evidenciando con ello una alta competencia del profesorado, atributo que contribuye a la acreditación de la oferta educativa orientada para el tercer decenio del Siglo XXI.

\section{REFERENCIAS BIBLIOGRÁFICAS}

ABET Inc. (2006). Engineering Change. A Study of de Impact of EC2000. Executive Summary.Lisa R. Lattuca, Patrick T. Terenzini, and J. FredricksVolkwein. Center for the Study of Higher Education, The Pennsylvania State University.En línea. Recuperado de http://www.abet.org/wp-content/ uploads/2015/04/EngineeringChange-executivesummary.pdf Consultado 10-10-2015.

ABET Inc. (2015). Accreditation Policy and Procedure Manual Effective for Reviews during the 20152016. AccreditationCycle. Recuperado de http:// www.abet.org/wp-content/uploads/2015/05/ A001-15-16-Accreditation-Policy-and-ProcedureManual-03-19-15.pdf Consultado 02-19-2015.

ABET-ESPOL. (2015). Proyecto ABET-ESPOL. Recuperado de http://www.abet.espol.edu.ec/ Consultado 20-10-2015.

Ayuga-Téllez, E., González-García, C., y Grande-Ortiz, M. A. (2010). Análisis de competencias en el Grado de Ingeniería Forestal para su adaptación al Espacio Europeo de Educación Superior. Formación universitaria, 3(3), 3-14. Recuperado de http://www. scielo.cl/pdf/formuniv/v3n3/art02.pdf Consultado 29-04-2015.

Bahillo, C. G., y Campillo, M. G. (2015). Retos y cambios en la organización universitaria. Hacia un nuevo modelo de enseñanza-aprendizaje. Revista Internacional de Organizaciones, (13), 85-109. Recuperado de http://revista-rio.org/index.php/revista_rio/article/ view/163 Consultado 02-09-2015.

Benítez, A. A., y García, M. L. (2013). Un primer acercamiento al docente frente a una metodología basada en proyectos. Formación universitaria, 6(1), 21-28. Recuperado de http://www.scielo.cl/scielo. php?pid=S0718-50062013000100004\&script=sci_ arttext\&tlng=pt. Consultado 01-09-2014.

Blaschke, L. M. (2012). Heutagogy and lifelong learning: A review of heutagogical practice and selfdetermined learning. The International Review of Research in Open and Distributed Learning, 13(1), 56-71. Recuperado de http://www.irrodl.org/index. php/irrodl/article/view/1076. Consultado 14-022015.

Brunner, J. J., y Ferrada Hurtado, R. (2011). Educación superior en Iberoamérica: informe 2011. RIL. Recuperado de http://dide.minedu.gob.pe/ 
xmlui/bitstream/handle/123456789/1098/647.\%20 Educaci $\%$ C 3\%B 3n $\% 20$ superior $\% 20$ en $\% 20$ Iberoam\%C3\%A9rica.\%20Informe\%202011. pdf?sequence $=1$. Consultado 14-02-2015.

Cochrane, T., Antonczak, L., Gordon, A., Sissons, H., \&Withell, A. (2012).Heutagogy and mobile social media: post web 2.0 pedagogy. In ascilite (pp. 204-214).Recuperado de http://ascilite.org.au/ conferences/wellington12/2012/images/custom/ cochrane,_thomas_-_heutagogy_and_mobile.pdf. Consultado 03-10-2015.

CONFCA (2010). Informe de homologación, equiparación y unificación de las carreras de Ingeniería Agropecuaria del Ecuador. Cuenca: Consejo Nacional de Facultades de Ciencias Agropecuarias y Afines del Ecuador.

Curiel, M. M. (2010). El proceso de Bolonia y las nuevas competencias. Tejuelo: Didáctica de la Lengua y la Literatura. Educación, (9), 19-37. Recuperado de http://dialnet.unirioja.es/servlet/ articulo?codigo=3719324 Consultado 01-08-2015.

De Donini, A. M. C. (2011). Internacionalización e integración de los sistemas de educación superior en el MERCOSUR educativo. RASE: Revista de la Asociación de Sociología de la Educación, 4(1). Recuperado de http://rase.ase.es/index.php/RASE/ article/view/147. Consultado 04-08-2015.

Delors, J. (2013). Los cuatro pilares de la educación. Galileo, (23). En línea. Recuperado en: http://www. ucuenca.ec/ojs/index.php/galileo/article/viewFile/169/166.104-105 Consultado 01-10-2015.

Díaz-Barriga Arceo, F. (2010), "Los profesores ante las innovaciones curriculares", en Revista Iberoamericana de Educación Superior (RIES), México, IISUEUNAM/UNIVERSIA, vol. 1, núm. Recuperado de http://ries.universia.net/index.php/ries/article/ view/35. Consultado 12-06-2015.

Fernández, J. V. M. (2009). La escuela centrada en la comunidad. Un modelo de escuela inclusiva para el siglo XXI. Revista Complutense de Educación, 20(1), 33-52. Recuperado de http:// revistas.ucm.es/index.php/RCED/article/viewFile/ RCED0909120033A/15367. Consultado 25-10-2015.

Ferreiro, R. (2010). El reto de la educación del siglo XXI: la generación N.Apertura impresa, (72:85). Recuperado de : http://www.redalyc.org/articulo. oa?id=68800506.

Galvis, R. V.(2007). Deunperfildocentetradicionalaun perfildocentebasadoen competencias. Universidad deLos Andes (ULA). pp 48 a 57. Recuperadodehttp:// www.saber.ula.ve/bitstream/123456789/17284/2/ articulo5.pdf Consultado 12-10-2015.

García-Manso, A., y Martín-Cabello, A. (2014). Aplicando el EEES en la Universidad española: un estudio de caso sobre la utilización de metodologías 2.0 en las nuevas titulaciones de grado. Historia y Comunicación Social, 18, 603-613. en línea. Recuperado de http://revistas.ucm.es/index.php/HICS/article/ view/43992/41597. Consultado 13-10-2015.

González Fontao, M. D. P., y Martínez Suárez, E. M. (2012). El profesor creativo y el profesor que potencia la creatividad en el contexto universitario. Recuperado de https://minerva.usc.es/handle/10347/4444.

González, J., Wagenaar, R., y Beneitone, P. (2004). Tuning-América Latina: un proyecto de las universidades. Revista iberoamericana de educación, 35(1), 151-164. Recuperado de http:// www.researchgate.net/profile/Robert_Wagenaar2/publication/28078676_Tuning-Amrica_Latina_un_proyecto_de_las_universidades/ links/0deec53c579b1998b4000000.pdf Consultado 21-12-2015.

Guerrero Chanduví, D. A., La Rosa Lama, G., y Palma Lama, M. (2014). Training and Competemces Development of Engineering Students in Project Management. Recuperado de http://ac.els-cdn. com/S1877042814012567/1-s2.0-S1877042814012567main.pdf?_tid=873af3dc-f762-11e4-888f00000aab0f27\&acdnat=1431296507_d92b0d1daa55a3e00c14b8ae3483ad66 Consultado 10-08-2015.

Hermo, J. P., y Verger, A. (2011). Las políticas de convergencia de la educación superior: un estudio comparado entre el proceso de Bologna y el MERCOSUR. Revista Cestão Universitáriana América Latina-GUAL, 3(1), 100-115. Recuperado de http:// stat.saudeetransformacao.incubadora.ufsc.br/ index.php/gual/article/view/790. Consultado 03-112015.

Hernández, J. M. O. (2014). La educación superior en México: un estudio comparativo. CIENCIA ergo-sum, 21(3), 181-192. Recuperado de en http://148.215.1.245/index.php/ergosum/article/ view/1607/1447. Consultado 02-07-2015.

Houtart, F. (2011). El concepto de Sumakkawsay (buen vivir) y su correspondencia con el bien común de la humanidad. Revista de filosofía,69(3). Recuperado de http://produccioncientifica.luz.edu.ve/index. php/filosofia/article/viewFile/18224/18212. Consultado 13-02-2015.

Imbernón-Muñoz, F., Silva-García, P. y Guzmán-Valenzuela, C. (2011). Competencias en los procesos de enseñanza-aprendizaje virtual y semipresencial. Comunicar, 18(36), 107-114. Recuperado de http:// www.revistacomunicar.com/indice/articulo. php?numero=36-2011-13 Consultado 22-05-2015.

Indígenas, P. (2004). Universidad Intercultural de las Nacionalidades y Pueblos Indígenas "AmawtayWasi». Ecuador/Chinchaysuyu. Instituciones Interculturales de Educación Superior en América Latina, 191-213. 
Recuperado de http://150.185.8.110/previo/ dmdocuments/biblioteca/libros/capitulos/INSTITUCIONES_INTERCULTURALES/II_CAP_6.pdf. Consultado 12-04-2015.

IPMA.(2006). ICB IPMA Competence Baseline 3.0.International Project Management Association.En línea. Recuperado de http://www. ipma.ch/assets/ICB3.pdf Consultado 01-01-2015.

Lagoria, S. L. (2013). Acreditación universitaria en el MERCOSUR y la UE. Integración y Conocimiento, (1). Recuperado de http://revistas.unc.edu.ar/ index.php/integracionyconocimiento/article/ view/5895. Consultado 20-04-2015.

López, C. R. (2012). Contextos de la innovación educativa. Innovación educativa, (22). Recuperado de http://www.usc.es/revistas/index.php/ie/article/ view/724. Consultado 02-09-2015.

Mas Torelló, Ó. (2011). El profesor universitario. In Profesorado: revista de currículum y formación del profesorado (Vol. 15). Recuperado de http://ddd.uab. cat/record/112747/. Consultado 15-05-2015.

Matheson, D. (Ed.). (2014). An Introduction to the study of education.Routledge. REcuperado de http:// samples.sainsburysebooks.co.uk/9781136253959_ sample_695929.pdf. Consultado 14-09-2015.

Medero, D. D. D., Rodríguez, J. C. Q., Guerra, M. Á., y Âlvarez, L. B. (2012). Perfil de competencias de profesores universitarios para la gestión de proyectos internacionales. Universidad y Sociedad, 4(3). Recuperado de. Disponible en http://rus.ucf.edu. cu/index.php/rus/article/view/274 Consultado 0303-2015.

Mena, A., Carvajal, D., Téllez, A., Barranco, C., Gallego, J. M., yBellido, M. (2009). Desarrollo de competencias en Dirección de Proyectos en los alumnos de las titulaciones de ingeniería industrial en la Universidad de Huelva (España). In Actas del XIII Congreso Internacional de Ingeniería de Proyectos, Badajoz (pp. 8-10). Recuperado de http://aeipro.com/files/ congresos/2009badajoz/ciip09_2227_2236.2654.pdf. Consultado 30-04-2015.

MERCOSUR EDUCATIVO. (2015). Presidencia ProTempore Brasil 2015. Plan 2011-2015. Recuperado de http://edu.mercosur.int/es-ES/plano-2011-2015. html. Consultado 05-08-2015.

Minguet, P. A., y Solís, A. U. (2009). La formación de competencias básicas para el desarrollo sostenible: el papel de la Universidad. Revista de Educación, (1), 219-237. Recuperado de http://dialnet.unirioja. es/servlet/articulo?codigo=3019436. Consultado 10 12-2015.

Molina, M. (2013). La revalidación de títulos universitarios en el MERCOSUR. Integración y Conocimiento, (1). Recuperado de http://www.revistas.unc.edu. ar/index.php/integracionyconocimiento/article/ view/5702 Consultado 20-04-2015.

Morales Morales, R., y Cabrera Cuevas, J. (2012). Competencias docentes transversales, el método de selección MiZona-CDT. REDU. Revista de Docencia Universitaria, 10(2), 75-101. Recuperado de http:// red-u.net/redu/index.php/REDU/article/view/402 Consultado 12-05-2015.

Morgado, E. M. M. (2010). Gestión del conocimiento en sistemas "e-learning", basado en objetos de aprendizaje, cualitativa y pedagógicamente definidos. Universidad de Salamanca. Recuperado de http:// dialnet.unirioja.es/servlet/dctes?info=link\&codigo $=1$ 8457\&orden=234517 Consultado 13-05-2015.

Nieva Fenoll, J. (2015). Docencia e investigación: un difícil equilibrio tras el impacto de la reforma de Bolonia. REDUCA (Derecho), 5(1). Recuperado de http:// www.revistareduca.es/index.php/reduca-derecho/ article/view/1845. Consultado 30-04-2015.

Nordin, N., Embi, M. A., \& Yunus, M. M. (2010). Mobile learning framework for lifelong learning. Procedia-Social and Behavioralsciences, 7, 130-138. Recuperado de http://ac.els-cdn.com/ S1877042810020239/1-s2.0-S1877042810020239main.pdf?_tid=2e7234c2-ac94-11e4-8d47-00000aa bof02\&acdnat=1423071496_551f0e4a376401223b 15701fcdca19af doi:10.1016/j.sbspro.2010.10.019 Consultado 20-10-2015.

Noriega, J. A. V., Moran, L. E. T., y García, E. E. M. (2014). Evaluación de competencias básicas en tic en docentes de educación superior en México.PixelBit: Revista de medios y educación, (44), 143-155. Recuperado de http://dialnet.unirioja.es/servlet/ articulo?codigo=4532180. Consultado 09-08-2015.

Nosiglia, M. C., Zaba, S. M., Mulle, V., y Polzella, Á. (2013). Los procesos de de acreditación de las carreras de grado de ingeniería y agronomía. Una mirada sobre la participación de actores. Recuperado de en https://repositorio.ufsc.br/handle/123456789/114948 Consultado 30-04-2015.

OEI. (2010). Metas Educativas 2021: la educación que queremos para la generación de los Bicentenarios. Organización de Estados Iberoamericanos para la Educación, la Ciencia y la Cultura. ISBN: 978-847666-224-3.. Recuperado de http://www.oei.es/ metas2021/ibro.htm.

ONU Organización de las Naciones Unidas. Declaración Mundial de los Derechos Humanos. Recuperado de http://www.un.org/es/documents/udhr/ history.shtml. Consultado 10-12-2015.

Ortega, M. (2010). Competencias emergentes del docente ante las demandas del espacio europeo de educación superior. Universidad Nacional de Educación a Distancia UNED. Revista Española de Educación Comparada. 16 (2010) 305-327. Recupe- 
rado de http://web.usbmed.edu.co/docbiblioteca/ competencias_emergentes_del_docente.pdf. Consultado 10-08-2015.

Palma Lama, F. M., Miñán Ubillús, E. A., y Ríos Carmenado, I. D. L. (2011). Competencias genéricas en ingeniería: un estudio comparado en el contexto internacional. Recuperado de. http://oa.upm. es/12804/1/INVE_MEM_2011_107508.pdf. Consultado 29-04-2015 Consultado 23-03-2015.

Panambi, A. (2009). Una mirada desde la educación superior a la experiencia del foro de decanos de agronomía del MERCOSUR. Educación Superior y Sociedad, 14(1), 61-72. Recuperado de http://ess. iesalc.unesco.org.ve/index.php/ess/article/viewArticle/52 Consultado 26-06-2015.

Panambi, A. (2009). Una mirada desde la educación superior a la experiencia del foro de decanos de agronomía del MERCOSUR. Educación Superior y Sociedad, 14(1), 61-72. Recuperado de http://ess. iesalc.unesco.org.ve/index.php/ess/article/viewArticle/52 Consultado 12-02-2015.

Pérez-Esparrells, C. y Casani, F. (2012). El programa Campus de Excelencia Internacional en España y algunas estrategias de universidades de la Comunidad de Madrid para mejorar su posición en los rankings globales. En línea. Disponible en http://repec. economicsofeducation.com/2014valencia/09-18.pdf. Consultado 09-02-2015.

Restrepo, J. M. (2005). El sistema de créditos académicos en la perspectiva colombiana y MERCOSUR: aproximaciones al modelo europeo. Revista de la Educación Superior, 34(3), 131-152. En línea. Disponible en http://xa.yimg.com/kq/ groups/23491751/752340976/name/restrepo_creditos_135.pdf\#page=133. Consultado 26-04-2015.

Rodríguez, M. D. L. E. I. (2010). Gestión docente en la administración de educación a distancia. Educare, 12(1). En línea. Disponible en http://revistas.upel. edu.ve/index.php/educare/article/view/57 Consultado 20-01-2015.

Russo, R. (2013). Capacidades y competencias del Extensionista Agropecuario y Forestal en la Globalización. Revista Comunicación, 18(2), 86-91. En línea. Disponible en http://tecdigital.tec.ac.cr/servicios/ ojs/index.php/comunicacion/article/view/857 Consultado 09-05-2015.

Ruz, T. P., Ramos, E. E., y Martín, C. (2012). Algunas cuestiones relevantes en la enseñanza de las ciencias desde una perspectiva Ciencia-TecnologíaSociedad. Revista Eureka sobre enseñanza y divulgación de las ciencias, 9(1), 71-77. En línea. Disponible en http://rodin.uca.es/xmlui/bitstream/handle/10498/14625/4_Prieto_et_al_2012. pdf?sequence $=6$. Consultado 13-02-2015.
Sáez, F. (2013). Hacia una estética del aprender: una experiencia de autosubversión pedagógica. Revista electrónica Diálogos Educativos. ISSN 0718-1310. Vol. 13 (2013) (22-41). En línea. Disponible en dialnet.unirioja.es/descarga/articulo/4414906.pdf Consultado 02-06-2015.

Sáez, F. T. (2012). Enseñanza basada en proyectos: una propuesta eficaz para el aprendizaje y el desarrollo de las competencias básicas. Revista Eufonía-Didáctica de la Educación Musical, (55), 7-15. Recuperado de http://fernandotrujillo.es/wpcontent/uploads/2012/09/articulo_Eufonia_final. pdf. Consultado 10-12-2015.

Salaburu, P., Haug, G., y Mora, J. G. (2011). España y el proceso de Bolonia. Un encuentro imprescindible. Edit. Academia Europea de Ciencias y Artes. Recuperado de http://www.expertosbolonia.es/ wp-content/uploads/2014/03/Espana-y-el-procesode-Bolonia.pdf. Consultado 30-05-2015.

SENPLADES (2014). Plan Nacional del Buen Vivir. Secretaría Nacional de Planificación y Desarrollo del Ecuador. ISBN 978-9942-07-448-5. En línea. Disponible en http://www.buenvivir.gob.ec/. Consultado 13-02-2015.

Silvio, J. (2010). La virtualización de la educación superior: alcances, posibilidades y limitaciones. Educación Superior y Sociedad, 9(1), 27-50. Recuperado de http://www.iesalc.unesco.org.ve/ess/index.php/ess/ article/viewFile/302/256 Consultado 25-05-2015.

Torra, I., De Corral, I., Pérez, M. J., Triadó i Ivern, X. M., Pagés, T., Valderrama Vallés, E., y Tena, A. (2012). Identificación de competencias docentes que orienten el desarrollo de planes de formación dirigidos a profesorado universitario. Red U. Revista de Docencia Universitaria, 2012, vol. 10, num. 2, p. 21-56. Recuperado de http://diposit.ub.edu/dspace/ handle/2445/42631. Consultado 30-04-2015.

Tünnermann Bernheim, C. (2010). La educación permanente y su impacto en la educación superior. Revista Iberoamericana de Educación Superior, 1(1). Página 131. Recuperado de http://ries.universia.net/index.php/ries/article/viewArticle/25 Consultado 12-07-2015.

Vicente, J. A. L. (2008). El Espacio Europeode Educación Superior. Educación y Futuro: Revista de investigación aplicada y experiencias educativas, (18), 71-90. Recuperado de http://dialnet.unirioja.es/descarga/ articulo/2572068.pdf. Consultado 20-01-2015.

Zabalza, M. A. (2012). El Espacio Europeo de Educación Superior. (69=95) En línea. Recuperado de http:// dspace.usc.es/bitstream/10347/4437/1/06.Zabalza. pdf. Consultado 30-04-2015. 